\title{
THE SPEED FACTOR IN INTELLIGENT REACTIONS.
}

BEING A THESIS SUBMITTED FOR THE DEGREE

OF DOCTOR OF PHILOSOPHY OF THE

UNIVERSITY OF EDINBURGH, APRIL 1931.

BY

JOHN DERG SUTHERLAND, B.SC., B.Ed.
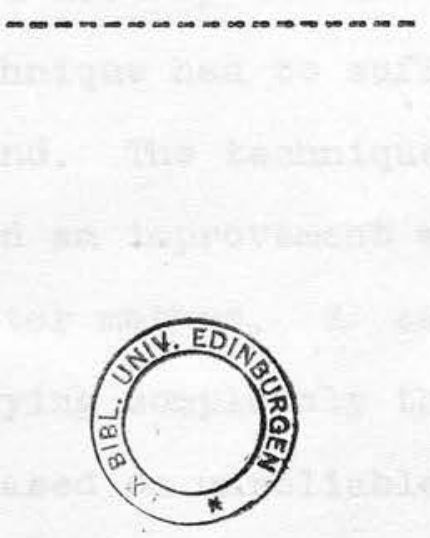

Degree conferred, $2^{2 m}-\sqrt{u b y} .1931$. 


\section{P R E F A E.}

The present inquiry was started with a much more specific aim than that which it later developed. In october 1928 was published a startling announcement of a very high relationship between reflex speed and intelligence. This result was so strange that it was taken by many psychologists "cum grano salis"; but it was obviously of surpassing interest if true. Then must the psychology and measurement of intelligence have been revolutionized. Here was the realization of the intelligence tester's dream - a single physiological measure obtainable very early from the subject and independent of environment. Here was "g". The figures quoted appeared strikingly significant, $r=.87 \pm .04$ from two groups of over 40 subjects. Such a result must be thoroughly tested before it would be time to interpret it with its probably farreaching effects. With this end in view, work was started. The expense of the method used by the American authors was prohibitive so a much cruder technique had to suffice. With this method no relationship was found. The technique was far too crude, however, to be trustworthy and an improvement was sought. Before I had succeeded with a better method, a second article appeared from the chief author denying completely the previous finding and explaining this as based on unreliable data. Since the data this time seemed to have been subjected to rigorous tests, the finding of no relationship was accepted and other more general problems were then considered. That further work was necessary upon some of these seemed apparent, and it is hoped that the results obtained 
will be of some interest and value.

To my mentors, Dr.Drever and Professor G.H.Thomson, I am greatly indebted. I wish to thank also the members of the staff of the Psychology Department, especially Mr.George Seth for help with the gathering of the data, the headmasters who permitted the measurements to be made, and Mr.Alexander Robertson for being a long-suffering subject and for countless hours of labour in obtaining the data and checking most of the calculations. For grants towards the cost of apparatus and material, my thanks are given to the Moray Endowment Committee.

JOHN D.SUTHERLAND.

April, 1931.

Psychology Department, University of Edinburgh. 


\section{THE SPEED FACTOR IN INTELLIGENT REACTIONS.}

CHAPTER I - INTRODUCTION AND PROBLEMS.

The Complaint against Time Limits in Intelligence Tests. The Conflict in Popular and Expert Opinions Regarding the Influence of the Time Factor.

Three Problems from the Criticism of the Time-Limit Tests.

(i) The effect of time limits on the validity of intelligence tests.

(ii) The existence of a factor of quickness in intelligent reactions.

(iii) The nature of the time differences in intelligent reactions.

Résumé.

CHAPTER II - EVIDENCE FROM PREVIOUS WORK BEARING UPON THESE THREE PROBLEMS.

1. Previous Work and the Validity of the Time-Iimit Tests.

The Army Investigation - Ruch and Koerth -

Extensive Data of Walters - Freeman - Own Data.

Summary and Conclusions on this Question.

2. Previous Work and the Existence of a Factor of Quickness in Intelligent Reactions.

Relationship between Level and Speed when measured Separately.

Hart and Spearman - McCall - Highsmith - Thorndike and His Students; Hunsicker and Clark - Walters' Data: An Important Point from These - Kennedy.

Objections to These Results as Showing a Factor of Speed in Intelligent Reactions.

A better Conception from Bernstein - Doubts regarding His Data.

Summary of Previous Work and Conclusions Regarding the Existence of a Speed Factor. 
3. Analytical Data: The Nature of the Speed Differences in Intelligent Reactions.

A Suggestive Contribution of Peak and Boring The Localization of the Speed Differences not Confirmed by other work - Intelligence and Speed of Association - and Speed of Reaction and "Serial Reaction" Speed.

Reflex Speed and Intelligence - Rounds - Travis. Conclusions.

CHAPTER III - PRESENT INVESTIGATION: AIMS AND PRINCIPLES DIRECTING THE EXPERIMENTS.

Aims and Statement of Problems.

Principles Directing the Attempts to Answer These.

Problem 1. - Crucial Tests for the Existence of a Speed Factor.

Problem 2. - Can we Analyse the Speed Differences Proposed Analysis by the Use of Performance Tests -

Data from Temperament Tests.

Scheme of the Experiments.

CHAPTER IV - METHODS AND RESULTS.

1. Statistical Evidence on the Existence of a Speed Factor in Intelligent Reactions from

(a) The Intercorrelations of the Times taken to do Simple Tasks.

(b) The Intercorrelations of the Scores Made in Tests of Medium Difficulty but answered under Highly Speeded Conditions.

Conclusions from these Results.

(c) The Speed Factor in Reactions of Very Low Difficulty and Its Relation to Intelligence. 
(d) A Group Factor of Speed in Intelligent Reactions Independent of " $g$ "

2. Analytical Data on the Speed Factor.

(a) The Nature of the Time Differences in Solving Performance Tests.

(b) Temperamental Traits and Speeds in Intelligent Reactions.

CHAPTER V - SUMMARY AND CONCLUSIONS.

APPENDIX - The Reflex Latency and Intelligence. BIBIIOGRAPHY. 


\section{CHAPTER I.}

INTRODUCTION and PROBIEHS.

I. THE COMPLAINT AGAINST TIME IIMITS IN INTELLIGENCE TESTS.

That those who think quickly need not be those who think well is a popular tradition which has been voiced in complaints against certain intelligence tests. These tests are the popular group tests in which the intellectual work done within a given time is used to give the ranking for intelligence. The complaint is that this ranking is materially influenced by speed of work, whereas it should be representative of intelligence alone.

Evidently the complaint is based upon assumptions regarding what should be measured by intelligence tests and how this measuring should be done. It is assumed that speed of work in the tests may be unrelated to intelligence, that one individual may do well, simply because he can answer the questions more quickly than another who is really more intelligent. Intelligence is thus taken to be the ability to perform eventually certain tasks which are judged to test goodness of thought. A measuring scale for intelligence should therefore have tasks forming a series of increasing difficulty. The subject should be asked to work up this series until he is unable to do any more, being given as much time as he chooses for this procedure. In this fashion will the abilities of the individual be exhausted and a valid measure of his intelligence obtained.

But in the time-limit tests, this does not occur. Instead, were they given more time, some of the testees would score full, or nearly full, points; and certainly most of them would add to their 
score. Nor is this lack of exhaustion of the testees' abilities the only fault. The attitude of haste is definitely demanded by the instructions. Subjects are told, in many cases, the actual time they will be allowed, as a further incentive to work as quickly as possible.

Therefore, it is urged, discrimination by these tests is not based primarily, as it should be, upon differences in intelligence Rather are the subjects differentiated by rate of work in the test items; and this characteristic of rate may be uncorrelated with the essential trait; which we might describe more exactly as the "level of intelligence".

A distinction has thus been drawn between what have been termed "speed" and "power" tests. In the former, quickness of work is introduced, while in the latter, the "power" or "level" of the intelligence is emphasized and is measured independently of the time factor.

(Because of the association of speed with the word "power", and its other meanings in everyday use, we shall use the term "level" to indicate this characteristic of intelligence which is measured when the abilities of the subject have been exhausted in a series of tests of increasing difficulty).

These "level" tests are held to be the ideal ones by most psychologists, but, because of the need of getting a measure of intelligence quickly and from a number of individuals at the same time, the group test with its strict time limits is more widely used. 2. THE CONFLICT IN BOTH POPULAR AND EXPERT OPINIONS REGARDING THE INFLUENCE OF THE TIME FACTOR.

In the original methods of measuring intelligence, this 
time question did not arise, for Binet's method conformed to the apparently ideal one of finding the degree of difficulty of the problems which the intelligence could just solve, when the testees were allowed as much time as they wished. He was thus measuring level of intelligence relatively independently of the speed of response. His brilliant contribution was the devisal of a scale of ascending difficulties to measure level in the convenient units of mental years. Time limits had to be introduced occasionally in practice but these were more for convenience than hard and fast limits by which the subject was given full credit or nothing at all. And this method was maintained in the revisions of the Binet scale. For example, in the Stanford Revision, we find Terman,

(42) supplementing the instructions to one of the tests (VIII - 2) with these words: "We agree with Bobertag that owing to the nature of this test we should not be pedantic about the time. While a majority of children who are able to count backwards do the task in twenty seconds, there are some intelligent but deliberate subjects who require as much as thirty-five or forty seconds." Here we have a liberal time limit allowed; yet the possibility is acknowledged that individuals have the ability to perform the test, although not within the chosen time. Moreover, they are to get credit for this slow response.

Again, for test $\underline{X}$ - Alternative test 3, we are required not to "tell the subject to see how quickly he can do it. Say nothing that would suggest hurrying, for this tends to call forth the trial-and-error procedure even with intelligent subjects". It was the introduction of the time-limit tests, with 
emphasis upon speed of work, which aroused criticism. Despite the fact that the new tests were constructed by experiment to measure intelligence a hostile attitude to their validity prevailed. Nor was the antagonism dispersed by results which showed the scores on these tests to correlate highly with the usual criteria of intelligence, and, in some cases, with the approved Binet measures. Possibly it was maintained by the testees. Certainly one of the first remarks one is likely to hear after giving a group test to adult subjects is, 'I could have done better with more time'.

The attitude of the test constructors to this complaint of lack of time was not a very sympathetic one. Since the time limits were generally chosen so that the brighter subjects could finish, it was maintained that those who did not exhaust their abilities within the allotted time failed to do so because they were duller than those who did finish. And indeed, there was widespread support for this view in popular opinion. To many, the slow were the dull and the quick, the bright. Such was the opinion expressed by Mr.Bennet in "Pride and Prejudice" when he described his daughters:

"They have none of them much to recommend them........... they are all silly and ignorant like other girls;- but Lizzy has something more of quickness than her sisters".

From this complexity of opinions, certain issues must be separated for consideration. Many of these are obviously important to the psychologist, both for his practical work of measuring intelligence, and for his interpretations of the nature of intelligence. A separation of these issues will, of course, be chiefly for convenience, not necessarily because they are essentially different 
and independent. Indeed, they are closely interrelated as will be seen later.

3. THE PROBLEMS INVOLVED IN THE CRITICISMS OF THE TIME-LIMIT TESTS.

We have found it useful to separate three problems from the general criticism that time-limit tests are not valid measures of intelligence. It is to be remembered, as we have just said, that these problems may not be distinctly independent, but at present they are probably best treated separately.

These problems are as follows:-

1. Are time-limit tests impaired as measures of intelligence because of the limits preventing all subjects from exhausting their abilities?

2. Can an individual be quick in the items of the intelligence tests without being at the same time of 'good intelligence'; or as we should prefer to say, of high level of intelligence?

3. What is the nature of the time differences in these tests?

\section{THE VAIIDITY OF THE TIME-IIMIT TESTS.}

This first question is a merely practical one. What effect is there on the validity of an intelligence test as a measure of level of intelligence when the subjects are told to stop working before many have finished? Methods of answering this question are obvious. If the testees were given as much time as they desired, the scores in this extended time would be indicative of nothing but level of intelligence. Hence these scores could be correlated with the scores made in the restricted time, and if this relationship turned out to be very high, then the time limits are clearly having little or no effect upon the goodness of the measure of level from 
from this test.

Another method of observing the effect of the time limits would be to correlate both the restricted time scores and the scores made when no time limit was imposed with some admittedly reliable criterion of level of intelligence, for example, the Binet mental age. If both sets of scores were equally related to this valid measure, then there would be no need to remove the time limits. Since we could get as good an assessment of intelligence with restricted time as with extended time, we might as well save the difference in time.

On the other hand, should the scores in the limited time not be highly correlated with those obtained in the longer time, it would be clear that we were not measuring the same function under the two sets of conditions. The criticisms against the tests suggest that a low relationship would be the result from such an experiment. only the long time scores would be valid, and only these would be expected to correlate highly with a reliable criterion. Previous work provides a large amount of evidence for a judgment to be made upon this question and we shall consider these results later.

\section{IS THERE A QUICKNESS IN INTELLIGENT REACTIONS?} OUR CONCEPTION OF THIS FACTOR.

The complaint against the time limit has an assumption of great interest to the student of the psychology of individual differences. This is that there exist differences in the speed of work in these tests which are uncorrelated, or, at least, not highly correlated, with the characteristic we have called level of intelligence. The phrase "in these tests" is of particular interest, and 
we emphasize it since it seems to have escaped the notice of most psychologists when considering this matter.

Individual differences are known to exist in the speeds at which simple cognitive processes can be performed, processes like cancellation, solving easy arithmetical problems, and completing substitution tests, being the usual ones studied. These differences are deep-rooted because they have been shown to persist when the subjects have used maximum effort and after extraneous factors, such as the amount of previous training, have been eliminated. It has also been shown that there is a slight tendency for certain individuals to be consistently quick in different types of these processes and hence these individuals have been described as having a general ability for speed in their 'mental reactions'. Further, this speed ablitity has been proved to be largely independent of intelligence. Here, it would seem, is direct evidence for the existence of a type of person who is quick in his 'mental reactions', yet not necessarily brighter than one who is slower. Therefore a time limit test is very much in favour of the quick person from the point of view of giving him a ranking for intelligence.

It must be noted, however, that, in measuring this speed ability, it is stressed that the tests must be simple, like the examples given before. If difficult, the times taken to do them are not measures of the individual's speed abllity because his speed of Work is practically obscured by this difficulty factor. This speed ability seems to be a peculiar facility in the well-worn paths of simple associative processes. There is thus a difficulty confronting those who assert a speed ability of this nature as a factor to be 
taken into account in measuring intelligence by time limit tests. This difficulty is the very obvious one that the material of these intelligence tests is not simple. The tests require intelligence; and the time taken to respond is affected very much by the presence of a "hardness" or level factor. And since it is stated by the psychologists, who have measured this speed ability as described, that the presence of the factor of difficulty or level invalidates a test as a measure of speed, we fail to see how this general speed in 'mental reactions' can have any influence at all in the intelligence tests.

It seems to us that the particular quickness underlying the complaint against these tests should be of a different nature entirely. The complaint is definitely against a quickness of work in these tests which might be uncorrelated with the characteristic of level of intelligence. Thus it should be a quickness of intelligent process. The existence of this kind of quickness would require to be proved in a fashion as follows: Imagine several individuals solving a few problems of the type usually given in intelligence tests, and doing these as well and as quickly as they can. The problems, of course, must not be too difficult otherwise only a few subjects would succeed; but they are to require intelligence for success in them. Let the following data be recorded.

(1) The times required to solve those problems done correctly by alz. (2) A measure of level of intelligence for each individual, obtained from a series of tasks similar to those in (1) but where the tasks are of increasing difficulty. In getting this measure, the subjects will be asked to do as many tasks as possible and 
will be allowed as much time as they wish. (This characteristic of difficulty is hard to define precisely, but roughly it may be described as follows (Thorndike) 'The harder the tasks a person can master, the greater is his level of intelligence, where hardness is described as the property of any one task in a series of tasks - all of which are homogeneous in nature and are judged by competent people to require intellect for their solution - which is associated with variation in the number of people from a group who can succeed with it, the fever of these, the harder being the task').

We know that the times taken in the problems solved by all will be partly dependent upon the level of intelligence; that brighter individuals will exhibit a tendency to solve problems in less time than duller ones will be unquestioned. Therefore we shall expect the times taken for two problems by the individuals of the group to correlate positively by virtue of this level factor alone. Suppose now that the influence of this factor is removed by mathematical treatment. Since we have a measure of level and of the times we can do this by "partialling" out the level factor. Then, if there is a quickness of intelligent process apart from level, the times taken to the two problems will still correlate positively from the common influence of this factor.

It is likely, of course, that the time taken to solve a single problem will not be a very reliable measure. To remedy this defect, the times taken in several problems could be combined. Two reliable time measures might be made in this fashion from two similar groups of tests. Then we should expect the partial cor- 
relation between these two composite times, after the level factor was made constant, to be positive, if there is a quickness of intelligent process as an individual difference, and to be negligible if no such ability exists.

Any factor of quickness revealed by a method like this one would certainly have to be considered in the measurement of intelligence. Of interest here, are some quotations from the reports of observers in Webb's investigation on "Character and Intelligence." (47). These observers were asked to estimate, among others, the following qualities:

(A), Quickness of Apprehension:

(B), Profundity of Apprehension:

(c), Power of getting through mental work rapidly. After the estimations had been made, the observers were asked to describe what they had understood by the qualities, and we give some of these interpretations.

For quality (A): "Quickness of grasping a truth or a problem"". " " (B) (i)" The subjects grasp not only the new truth or problem, but its relationship to other truths and problems at the same time".

(ii) "The + men perhaps did not see the point quite so soon as those in $\mathrm{A}$, but they grasped it more thoroughly, I think'"

" " (C): "The readiness with which his mind absorbs ideas. Another man might understand a thing equally well, but it takes him a much longer time". Proving the statements in $B(i i)$ and $C$ sums up admirably 
this question of whether or not, certain people can think more quickly than others and yet be incapable of such profound thought. 3.

If a factor of quickness in intelligent reactions were proved to exist independently of level of intelligence, its nature would be a further question requiring investigation. It would be an important individual difference to separate, and a very valuable trait to assess for vocational purposes. To know that one individual had a "quick intelligence" and another a "good" intelligence would be important information in the selection of employees for certain occupations. And it would be still more valuable knowledge if we knew why the one person was of quick, yet not very good, intelligence. This analysis of the factors making for differentiation in the speed of intelligent reactions will be of value, of course, independently of the existence of a separate quickness. For if there be no quickness apart from level in these reactions, then, as Boring (33) has pointed out, the analysis of the speed factor will offer a direct experimental attack upon the nature of intelligence.

\section{RE S U M E.}

We have separated from the general question of the factor of speed in intelligent reactions three problems:-

1. The validity of the time-limit intelligence tests as measures of level of intelligence.

2. The existence of a quickness in intelligent reactions apart from level of intelligence. 
3, The nature of the speed differences in the intelligent reactions.

It will be clear, however, how intimately connected these problems are. The results of investigations on the first problem can be quoted as evidence towards the answering of the second; and if we separate a speed ability in intelligent reactions, we must obtain from this process some ideas regarding its nature. Their separation is convenient for various reasons. We have a useful means of reviewing the vast amount of assorted work which has been done on what has been loosely described as 'speed and ability'. We also have a simplification of a complex problem, when these 1ssues are taken one at a time. We shall show in the next section how well previous work answers these questions and then set forth the problems still unsettled and the methods we have adopted to answer these. 


\section{CHAPTER II.}

THE EVIDENCE FROM PREVIOUS WORK BEARING UPON THESE THREE PROBLENS.

I. UPON THE VAIIDITY OF THE TIME-IIMIT TESTS AS MEASURES OF LEVEL OF INTEIIIGENCE.

The complaint against the time limits in tests which were purporting to measure level of intelligence naturally arose early in the history of the group test method. When the subjects were prevented from exhausting their abilities, the scores obtained were said to discriminate on the bases of level plus speed in the problems instead of on the basis of level of intelligence alone. The merely practical aspect of the question was obviously one which could be settled by experiment. The subjects could be given as long a time for the tests as they wished and the scores obtained in this time compared with those made in the restricted time. The former would clearly be determined by level of intelligence alone, while the latter would be affected by the speed factor. Several experiments of this type were carried out and we shall examine these for reliable evidence upon this question.

\section{THE ARMY INVESTIGATION.}

The earliest of these investigations was one carried out by May (31) during the recent War, when 510 men were given the Army Alpha Test. With each sub-test in the series the men were asked to draw a line across the page at the point they had reached after standard time. They were then given another period equal to the first one with instructions not to change anything above the line. The single-time total scores correlated very highly with the double- 
time total scores, $r=.965$, and hence it was concluded that "we have no reason to assume that an extension of time limits would have improved the test or have given an opportunity to many individuals materially to alter their ratings".

The conditions in this experiment were not so rigorous as they might have been. An allowance of another standard time would still leave some subjects unfinished, and also, the subjects were prevented from correcting any errors made in the first period. The possibility of the subjects failing to finish even in the extra time is a serious objection, as Freeman has said (I7), to accepting this high relationship as a true picture of the correlation between the time-limit and no-time-limit scores. The period of extra time would be used, by those subjects who did not finish in it, in doing another portion of the test under similar conditions of restricted time. The correlation between the standard and extra time scores would therefore be not so much an indication of the relationship between scores obtained under hurried and leisure conditions as a mere measure of the reliability of the test.

\section{THE INVESTIGATION BY RUCH AND KOERTH.}

A similar study to the previous one was carried out by Ruch and Koerth (38) with student subjects. The conditions, however, were much more testing. The Army Alpha Test was given to the lowest and highest deciles of a large college group, this separation being obtained from the results of a previous test. The students were informed that they were to be given the chance of extra time to remedy the insufficient time at the previous similar test. Differently coloured pencils were used to get the scores under the 
conditions of

(i), standard time;

(ii), a further allowance of standard time; and (iii), under as long time as they pleased.

There were 122 cases, 70 in the lowest and 52 in the highest decile, and the correlations obtained were

(i) for single-with double-time scores $r=.966 \pm .004$

(i1) " single- with extended-time scores $r=\cdot 945 \pm .007$

Result (11) above is the interesting one for the question we are considering. It would certainly seem to show that the imposition of the time limit does not influence the measure of level, since the value of the relationship between the time-limit and no-timelimit scores is about as high as the reliability of the tests would allow.

It was pointed out by Highsmith (23) that a spuriously high value existed in these correlation coefficients of Ruch and Koerth, arising from the constitution of the group. The frequency distribution was quite abnormal with this slumping of the extreme deciles of a large group, the scatter being far too large. Highsmith showed from the original data that the relationships for the separate deciles were,

(i) Single- with double-time scores $\frac{\text { Lowest }}{r .86} \quad \frac{\text { Highest }}{r=.7 I}$ (ii) Single- with extended-time scores $r=.76 \quad r=.65$ And these, he suggested, were still too high because of the greater spread at the extremes of any group. This is doubtful however, as the effect of such selection is generally to reduce the correlation (8). The relationship between the standard and completely extended 
time scores is probably between the original values and those calculated from the separate deciles.

\section{THE EXTENSIVE EXPERIMENTS OF F.C.WALTERS.}

In 1929 Walters (46) published an extensive series of results dealing with the time factor in intelligence tests and many of these are of interest at this point.

To measure the extent to which an extension of time would alter the correlations between some valid criteria of intelligence and the scores of certain group tests, was one of his problens. He gave several of the better known tests to 165 children under conditions such that he could get measures of half-time, standard-time, and extended-time scores, these latter being the scores made under as long time as was desired. The subjects were all within a range of one school year, although the chronological age range was from 10 years 4 months to 15 years 5 months, with mean 12 years 5 months. The mental ages (Stanford Binet) ranged from 10 years to 16 years 10 months, with mean 12 years 1 month. The criteria with which the group test scores were compared were (1), Standford-Binet mental age, and (2), a composite of school marks, school progress, teachers' ratings, and the mental age (I).

As a supplementary test of the validity of the time-limit scores, he correlated these scores with the extended-time ones. He assumed from the beginning that standard-time scores were affected by the rate factor, and any lack of relationship between these scores and the pure "power" scores made in the extended time, would be indicative of the influence of this rate factor on the scores made in the restricted time. The following table gathers his results for 
the tests used (Table I.)

\section{TA B L E I.}

CORREIATIONS BETWEEN HALF-TIME, STANDARD-TIME, AND EXTENDED TINE SCORES IN FIVE GROUP TESTS FROM WALTERS' DATA.

\begin{tabular}{l|c|c|c}
\hline \multicolumn{1}{c|}{ Test. } & $\begin{array}{c}\text { Half and } \\
\text { standard } \\
\text { time. }\end{array}$ & $\begin{array}{c}\text { Half and } \\
\text { extended } \\
\text { time. }\end{array}$ & $\begin{array}{c}\text { Standard and } \\
\text { extended } \\
\text { time. }\end{array}$ \\
\hline National Intelligence Test A I & .872 & $.841(.936)$ & .883 \\
Otis Advanced Form A & .936 & .854 & .912 \\
Mentimeters & .952 & .839 & .892 \\
Indiana Cross-Out & & & .944 \\
Pintner Non-Language & & & $\frac{.831}{.892}$ \\
\hline
\end{tabular}

It will be seen that the values are all high, even between the half-time and extended-time scores. (The value in brackets represents the correlation for the National Test when the Symboldigit test is discounted, for under extended-time all subjects score practically full marks in this test.)

The relationships of the scores made under the different time limits to the criteria are given in Table II. With Stanford Binet mental age, the extended-time scores do not correlate any more than do the standard-time ones. In the case of the composite criterion, the extended-time relationships are slightly higher.

\section{TAB LE II.}

CORRELATIONS BETWEEN THE CRITERIA AND THE FIVE TESTS. (TABIE $X$ in Walters' Monograph).

Correlation for Tests below and Stan ford Binet Mental Age. 


\begin{tabular}{l|c|c|c|c|c}
\hline & N.I.T. & Otis & $\begin{array}{c}\text { Menti- } \\
\text { meters }\end{array}$ & $\begin{array}{c}\text { Cross- } \\
\text { out }\end{array}$ & $\begin{array}{c}\text { Non } \\
\text { Language }\end{array}$ \\
\hline Half-Time Score & .5812 & .6262 & .5866 & & \\
Standard-Time Score & .5896 & .6762 & .5997 & .5335 & .1287 \\
Extended-Time Score & .5994 & .6583 & .5820 & .5567 & .2745 \\
\hline
\end{tabular}

Correlation for the same Tests and the Composite Criterion

\section{Half-Time Score}

Standard-Time Score Extended-Time Score

\begin{tabular}{|l|l|l|l|l}
.6410 & .6723 & .5345 & & \\
.6487 & .7377 & .5925 & .5952 & .0919 \\
.7163 & .7906 & .6259 & .6355 & .2913 \\
\hline
\end{tabular}

A corresponding table to this one (Table II) is also shown, but with chronological age partialled out; the relationships, however, are very similar.

When the scores on all the tests are combined, the following results were obtained: (Table III).

$$
\text { TA B I E III. }
$$

\begin{tabular}{l|c|c}
\hline & Stanford MA. & Composite Criterion \\
\hline Total Score Standard-Time & .7132 & .8595 \\
Total Score Extended-Time & .7049 & .8539 \\
\hline
\end{tabular}

These results are highly convincing. They show that the time-limit group tests give practically the same rankings under their so-called speeded conditions as under the supposedly more valid conditions of no time-limits. If group tests are poor measures of intelligence, this fault lies in the nature of the test and has nothing to do with the time limits.

Walters remarked upon the imperfection of the relationships between standard- and extended-time scores, and he calculated the 
coefficient of alienation between the two measures to show the extent of the influence of the speed factor in the standard-time scores. supporting the view that these scores were influenced by the rate factor was the slightly higher correlation between the extended-time scores and the composite criterion for each test. Since he admitted that the scores from the two different time limits might be affected by extraneous factors, stressing this point as he does seems rather like stretching the facts to fit a preconceived theory. Some increase in the correlations with the criteria might be expected from the extended-time scores merely because they were obtained from longer tests. If we assume that his subjects did on the average about one tenth as much in the extension of time as they had done in the standard time, then, by the Spearman-Brown formula (8), a correlation of $r=.65$ would rise to $r=.67$, merely from the increase in rellability of the slightly longer test. If they did one fifth as much, it would rise to $r=.59$. Hence an average increase of .05 in the correlations with the test scores and the composite criterion due to the extension of time camot be taken as strong evidence in favour of the view that the time-limit scores are affected by the rate factor.

\section{FREEMAN'S RESULTS.}

Recently, Freeman (18) has supplemented some of his previous data on the relations between the extended- and standard-time scores. For three group tests, the correlations he obtained between these scores were as follow:-

$\begin{array}{ll}\text { for the National Intelligence Test, } & r=.83 \pm .02 ; \\ \text { "1" Otis Advanced } & r=.58 \pm .06 ; \\ \text { " "Terman Group Test } & r=.93 \pm .01 .\end{array}$ 
The otis test gave a very low value and he concluded on this account that the standard time score in this test was chiefly a measure of speed. As he had only 51 subjects, and of age not very different from those in Walters' investigation, Walters' result must be preferred $(r=\cdot 9 l)$ as the more probable.

\section{SOME DATA FROM AN EXPERIMENT OF OUR OWN.}

Additional data may be quoted which were obtained by us in the course of investigating another problem - hence not entered as part of our experimental inquiry. 36 children were given a battery of tests under speeded and no-time-limit conditions. The latter scores correlated with the first ones to $\cdot 85 \pm \cdot 03$.

SUMMARY OF THE EVIDENCE FROM PREVIOUS WORK UPON THE VALIDITY OF THE TINE-LIMTT SCORES IN INTELIGENCE TESTS AND CONCLUSIONS REGARDING THIS QUESTION.

When the results of previous investigations are brought together, we see that the correlation between the scores made under time limits and under conditions where the abilities are exhausted is in every case very high. On the average it is almost as high as the reliability coefficients of many of the measures. The various values obtained are given again below along with the weighted average. Because the Army investigation did not employ the essential condition of no time limit, it has been omitted. 


\section{T A B I E IV.}

CORRELATIONS BETWEEN STANDARD-TIME AND NO-TIME-LIMIT SCORES.

\begin{tabular}{l|l|l}
\hline \multicolumn{1}{c|}{ Investigator } & \multicolumn{1}{|c|}{ Test or Tests Used. } & Result. \\
\hline Ruch and Koerth & Army Alpha & $\cdot 945$ \\
Ruch & Terman (A further report by this author) & .960 \\
Walters & Total Scores in Five Group Tests & $\cdot 934$ \\
Freeman & Average for Three Group Tests & $\cdot 780$ \\
Own Data & Battery of Miscellaneous Tests & .85 \\
\hline
\end{tabular}

We therefore have concluded that the practical question of the validity of the measures obtained by the time-limit tests as rankings for level of intelligence has been answered satisfactorily. The assertion that increase of time would alter the rankings for intelligence which were obtained from the standard-time scores is unfounded. The evidence shows the standard-time scores to be very highly correlated with level of intelligence, so far as this is measured by the scores obtained in these tests when the time limits are removed. Thus the standard-time scores of the time-limit tests are practically unaffected by any independent rate factor.

The further implications of this result form another matter. 


\section{CHAPTHR II. (Continued)}

2. PREVIOUS WORK AND THE EXISTENCE OF A FACTOR OF QUICKNESS IN INTELLIGENT REACTIONS.

It seems to us that the results of the time extension experiments just quoted imply that good thinkers can be quick thinkers when the occasion demands this speed. If an ability for quickness in intelligent reactions existed independently of the level factor we should not expect such a high relationship as was actually found between the scores made when working against time and those made when the time restriction was removed. It is possible, of course, that the high relationship between these scores may signify that the standard time was really long enough for most subjects to exhaust their abilities and so the effect of any speed factor would be concealed. Or again, the score in extended time may not be a good measure of level because we know the tasks of the usual group test are not of regularly increasing difficulty. I'hat this extended-time score is not a good measure of level is suggested by the comparison of the rankings from an admittedly good measure of level of intelligence, say the Stanford Binet mental age, with the rankings based on these scores in extended time. Walters' data quoted previously showed that this relationship was only of the order of $r=\cdot 6-\cdot 7$; and other investigators have found similar figures. (35)

To those psychologists who assume a general rate factor in 'mental reactions' from the evidence of the performances in specially constructed speed tests, the results of the time extension experiments certainly do not negative the existence of a speed ability. We shall consider therefore the direct evidence for or against the 
existence of a factor of speed in intelligent reactions. THE RELATIONSHIP BE TWEEN LEVEL AND SPEED WHEN NEASURED SEPARATELY.

Amongst the investigations which are specifically concerned with this problem, the method adopted in many has been to attempt to measure separately the level and speed of response and thence to show the relationship between these measures. If this is low, it is concluded that speed of response is largely independent of intelligence. The usual methods of obtaining the measures are simple. Speed of response is determined from the performance in tests of which the material is of a very low degree of difficulty, e.g., cancellations, easy opposites, easy sentence completions of arithmetical problems, etc., while the measure of level is obtained from a test of intelligence. Many of the early investigations on the inter-correlation of various mental abilities provide data of interest here, but we have preferred to consider these results later. In other investigations, more rigorous methods have been used, namely, to examine the inter-correlations of the speed measures for correlation not dependent upon the intelligence factor, removing the influence of this by statistical methods.

Hart and Spearman (22) using both normal and abnormal subjects found no specific correlation between the scores in different speed tests such as cancellation, addition etc. The method of showing the absence of this was to remove the influence of " $g$ ", which of course, is a different question from the removal of intelligence as ordinarily used. But accuracy was not kept constant in the tests so that the speed data are of doubtful value.

One of the first to investigate the question of "speed" 
and "power" tests and their relation to intelligence seems to have been McCall (32). He distinguished the "power" test as, "one that contains units sufficiently difficult to discover the maximal

ability of the person or persons being measured". 88 children were given a series of speed tests of the usual types and also a series of "power" tests, while the criteria of intelligence were composites of all the tests, teachers' ranks, and school marks. The average correlation of the "power" tests with the intelligence measures was -69, while the average value of the speed tests with these measures was only .03 . Speed was thus concluded to be independent of intelligence.

Highsmith (23) published a rather important report in 1925. A short extract from his paper will give his problems. "To what extent is an individual's rate of response constant for different kinds of material responded to? Does rate of response vary with material of different leads of difficulty, and is this difference constant for various individuals? To what extent is intelligence a question of rate of response? Can rate of response in linguistic and non-linguistic materials be weighted with time-limited mental tests so as to improve the correlation with our criterion?"

The criterion was the Stanford Binet mental age. To answer these questions he obtained four measures; (1) the mental age as a measure of general capacity nearly independent of the time element; (ii) a measure including both the time factor and difficulty, a group test; (iii) and (iv) speed measures from tests of mimimum difficulty but of the same material as the intelligence tests, linguistic and non-linguistic tests being used. Three groups of 
subjects were used, about 30 in each group. The inter-correlations are given for the groups separately and for all the subjects put into one group. Since his subjects were selected, being of superior intelligence, we think the results obtained from the whole group are more reliable. (From his data it can be shown that in the slumped group the mental ages have a standard deviation of 22.6 months with a mean of 159 months - mean chronological age 147 months. This is not far from the range of ability in a normal group of this age). His chief results and conclusions are as follows,

where 1 . Stanford Binet M.A.

2 = National Intelligence score.

3 a Non-Linguistic Rate Tests.

4 = Linguistic Rate Test.

1. Rate of response is not a good measure of intelligence. Because $r_{13}=.33 ; \quad r_{14}=.56$; and $r_{1 \cdot 34}=.56$.

$\left(r_{1} \cdot 34\right.$ is the correlation between 1 and a combination of 3 and 4$)$. 2. 'The group test (National) is a better measure of rate of response than of intelligence, because

$$
\begin{aligned}
r_{12}=.64, & r_{23}=.57, \text { and } r_{2 \cdot 34}=.89 . \\
r_{24} & =.88,
\end{aligned}
$$

The difficulty confronting the assertion of an independent factor of speed from these results however is that it has been shown from the time extension experiments with the National Test that speed of response is not what is measured, otherwise the correlation between the time-limit scores and no-time-limit scores would be low.

\section{THE WORK OF THORNDIKE AND HIS STUDENTS.}

Extensive investigations on the relation between level of 
intelligence and the speed at which tasks can be performed have been carried out by Thorndike and his students (43). By means of his graded scale of increasing difficulty in sentence completions and arithmetical problems, very good measures of level were obtained. It will be seen of course, that these measures of level are in particular types of task. The tasks chosen, however, correlate highl with intelligence so that the measure is a fair index of level of intelligence. Speed was measured in tests using the same class of problem, but of very low difficulty.

Hunsicker (24) reported the results of a very careful investigation of this type. She obtained, by individual measurement, the times taken to do series of the easy tasks, and also the level reached by each subject in the increasingly difficult series. These rate and level measures from four groups of subjects gave an average correlation (corrected for attenuation) of .46 for arithmetic, and - 47 with the sentence completions. The average value for rate with rate was $\cdot 67$, and level with level .66 - both corrected. From these figures she inferred rate to be "an individual trait which is characteristic of mental behaviour."

Since the correlations with rate in one test and level in in the other are not given, it is not possible to calculate from her data how much of the correlation between the rates is due to such a trait or to the level factor.

Thorndike extended these results to the case of rate and level measured in the composite of tasks which he called the CAVD intellect. Here the measures correlated .42 (corrected). V, vocabulary, was a curious measure to introduce into the speed 
measures; possibly it was the source of the slightly lower relationship, although this was not considered.

An investigation by another of his students, Clark (11), gave additional data. Here, level and speed measures, as obtained by Hunsicker, were correlated with Stanford Binet mental age and with the scores in two group tests. The average of the six correlations between each of the two speed measures, speed in sentence completions and speed in arithmetic, and the three intelligence tests was .54. The average of the six level and intelligence test relationships was $\cdot 70$ - both values corrected for attenuation.

From these results Thorndike deduced certaln relations between "speed in general", "level in general", and the "tests in general", from formulae of the type,

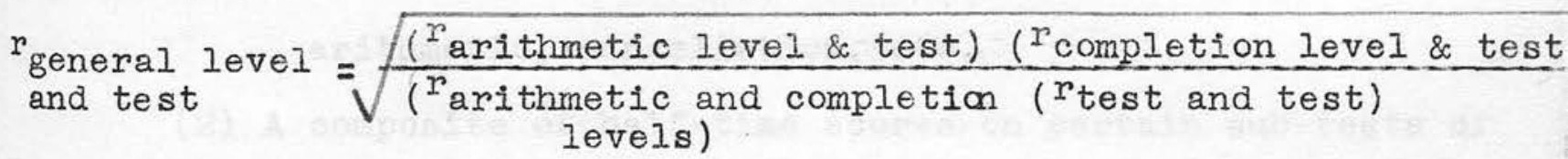
The average value of these relationships between general level and test scores is $\cdot 97$. Between general speed and test scores the average is .62 .

From the lowness of the relationship between the speed and level measures, Thorndike suggested that in measuring intelligence the speed of response should be measured separately since it seemed to be partly independent of the level factor.

\section{WALTERS' DATA ON THE EXISTENCE OF A SPEED FAC'TOR AND 'IHE} UNSATISFACTORY NATURE OF THESE.

Very comprehensive evidence was presented by Walters, in the monograph referred to previously (46), to show the existence of a speed factor. He also showed the influence of this factor in the 
time-limit intelligent test, but we shall confine our attention to the proof of its existence. Iike the previous workers under Thorndike, he assumed the existence of a speed factor from the beginning, and measured it in special tests of low difficulty. When such speed measures were related, they had high inter-correlations, whereas with measures of level of intelligence the speed measures correlated very lowly. The values of the speed-with-speed correlations ranged from $\cdot 4$ to $\cdot 7$, while the speed-with-intelligence relationships ranged from 0 to $\cdot 4$.

This evidence seemed to support his initial assumption of a factor of quickness in intelligent reactions, as his speed measures were not all of a very low difficulty. As measures of speed of work he used (1) a composite of low difficulty tests including reading, arithmetic, cancellation, etc.

(2) A composite of half-time scores on certain sub-tests of the National Intelligence Test and Otis Test Booklets.

(3) The amount of added-time taken by the subjects after the standard limits to finish the tests.

(4) A composite of the previous three.

In getting the speed scores, however, he chose the amount done in the tests, rather than the amount done correctly, because this latter was more indicative of ability than rate of work and his desire was to have the rate of work tests as free from the ability factor as possible.

AN IMPORTANT POINT FROM WALTERS' DATA.

This method of measuring the speed of work seems to us to vitiate completely his proof of the existence of a speed factor in 
intelligent reactions.

It is to be expected that, under conditions of unequal accuracy, different preferences might be exhibited for quick, or careful, work. But we cannot on these grounds say one subject is faster than another. It seems to us essential that in differentiating people on the basis of speed of response, the same work must be done by all. As Boring (33) has put it, "psychologically regarded accuracy can not be divorced from time", and if it is desired to compare different speeds, accuracy must be kept constant. 'lo say that a subject who rushes through a test and making many wrong answers, is faster than one who goes carefully, but makes perfect responses, is meaningless. Actually, Walters' measure of the anount attempted in half-time correlated with half-time score only to the extent of $\cdot 53$, as the average value from three tests. Again, the amount of added- time would appear to have doubtful value as a measure of rate of work. It correlated negligibly with the extended-time scores and was therefore thought to be little affected by the level factor. In reality it is almost cornpletely governed by this factor, for the subjects' level has everything to do with the amount of work to be done in the extra time. The brighter children will have relatively little to do, while the duller will only be able to do relatively little after the standard allowance of time.

The interpretation of Walters' results seems to be that there is a temperamental difference by which individuals prefer to have different attitudes to speed and to accuracy in their work. It certainly is not that a quickness of intelligence exists independently 
of level of intelligence.

\section{SPEED AS A PERSONALITY TRAIT.}

A research showing the existence of consistent differences in speed of work, independent of intelligence, was reported by Kennedy. (28). With one group of 20 graduates, she found an average correlation of $r=.45$ between the speed tests (easy arithmetic, sentences, opposites, simple reaction speeds, etc.,). A composite score of the speeds correlated .54 with the Army Alpha standard-time scores, but this value became zero when the double-time scores were used. Since she took these latter to be better measures of intelligence than the single-time ones, the author concluded that there was an independent factor of speed in mental reactions. The greater validity of the extended time scores is supported by a reference to Walters' data, where "extended-time scores had a slightly higher correlation with composite measures of intelligence than standard-time scores". This is hardly strong support however bearing in mind Walters figures. Certainly the reduction in the correlation which was obtained was large. With only 20 subjects, and remembering the probable poorness of discrimination in double-time scores with very bright subjects, it is not to be stressed.

With another group of 32 adult subjects similar results were got. The average intercorrelation of the speed tests was .42 , but the average of the speed-and-intelligence correlations was $\cdot 06$. When intelligence is partialled out, the speed tests correlate still, the average value of the partial correlations being $\cdot 36$. This supports the previous conclusion of a factor of speed independent of intelligence. Kennedy suggested that the basis of this factor, 
which she termed a personality trait, "irritability", was probably the existence of the popularly recognised personality types - rash, impulsive and slow, deliberate.

\section{OBJECTIONS TO THESE RESULTS AS SHOWING A FACTOR OF SPEED IN INTELIIGENT REACTIONS.}

The conclusions from these investigations are not, we think, to be so readily drawn as they have been. Difficulty arises evidently in what the various investigators are describing by the term "speed". The majority of these investigations stress very strongly the point that the speed measures must be obtained when the material is of zero difficulty, hence the use of tests which reduce to measures of simple sensori-motor, or association processes. We doubt very much whether such measures can be expected to reveal any trait which would be worthy of consideration in regard to the time taken in solving a problem. Such measures can only measure what might be described crudely as the smoothness of facility with which the machinery of fairly well-worn association paths can function. The tests are all of a very specific character and high intercorrelations would not be expected. But when significant correlation occurs after the intelligence level factor has been eliminated, it is immediately concluded that a group factor of speed exists in "mental reactions"; and of this we must beware when we are measuring intelligence by time-limit tests. It seems much more likely that the factors producing specific intercorrelation between these tests will be of the nature of a group factor in simple sensori-motor ability, such as Farmer has described in his "aestheto-kinetic" factor. We should not expect such a speed factor to be of great 
importance in the scores made in intelligence tests, for the material here requires intelligence in a quite different degree. We think the group factor which it would be important to separate in connection with the measurement of intelligence would be one existing in such a situation as described earlier (p.8). The speed measures of Thorndike's investigations for example would probably be governed by such extraneous factors as the amount of practice the subject had had in mental arithmetic; and it might be expected to depend on speed of handwriting. In the intelligence test we cannot deal with what has been described as "pure speed". What we must take account of is a speed of intelligent process, of the education of correlates and relations. The question must rather be - can one individual educe relations and correlates at a relatively simple level more quickly than another, without being able to educe more difficult relations and correlates, to solve more difficult problems, when this level ability is measured under conditions where speed is unimportant? In the words of Webb's subject, 'do the + men see the point more slowly, but yet grasp it more thoroughly, than the men who could grasp it quickly.'

This seems to us to be the important problem; that people need not think quickly to be capable of good or profound thought. From this point of view the results of the time extension experiments are of considerable significance; from the other point of view which seeks to isolate a "pure speed" they are incapable of interpretation because of the contamination from the power factor in these tests. From our point of view, the high correlation between the scores obtained under speeded conditions and those obtained 
when time is discounted is very suggestive that the time taken in solving problems is dependent chiefly on the level of intelligence. But as mentioned before the uncontrolled factors in the conditions of the experiment make precise interpretation impossible.

\section{A BETTER CONCEPTION OF THE PROBLEM IN BERNSTEIN'S INVESTIGATION, BUT HIS DATA NOT CIEARIY VALID.}

A much better conception of the nature of a speed factor in intelligent reactions guided the work of Bernstein (4) under Spearman's direction. He sought to show whether, or not, a group factor of quickness existed in the solving of problems ordinarily found in intelligence tests, apart from definite causes like defective conation, or perseveration. From his teaching experience he thought such a factor to exist, and indeed set out as a preliminary part of his work, several factors which seemed from careful observation to determine speed differences independently of general intelligence. His method of investigating the possible existence of a speed factor was first to obtain scores from tests of two types, (a), those in which ample time was allowed or "Leisure" Tests; (L)

(b), " " " the time allowed was too brief for all but the fastest subjects - or "Haste" tests (H).

He then examined the relationships of these measures with estimates of (i) intelligence, and of (ii) slowness, made by teachers, it being thought that the obverse aspect of a slowness apart from intelligence was more convenient to assess. Slower subjects, he expected, would do relatively better in the "Leisure" tests. Results showed, however, that the two kinds of test correlated equally with the estimates of intelligence and of slowness. And the crucial measure, the difference 
in the "Leisure" and "Haste" tests scores, scarcely showed significant relationship with any other measure or estimate. In particular, "the erucial correlation of $\mathrm{L}$ - $\mathrm{H}$ with the estimate of slowness was negligible". Hence he concluded that no group factor of speed existed. This conclusion he also supported by analytical data, for measures designed to assess possible constituents of the speed factor showed no relationship with the I - H values.

Spearman quotes these results at some length in the "Abilities of Man", and, using the tetrad difference criterion, shows that no specific correlation exists between the $L$ and $H$ measures either as a factor of quickness or of accuracy.

\section{DOUBTFUL VALIDITY OF BERNSTEIN'S DATA.}

While the principle of Bernstein's method seems admirable, the actual experimental conditions do not seem to be so. It seems extremely doubtful if the tests, as used, were capable of offering valid data for the problem. For example, a "Leisure" test in sentence completions consisted of four sentences, each having two missing words, while a "Haste" test consisted of sixteen sentences, each having one missing word. The "Leisure" completions thus were slightly more difficult. All the tests were given for thirty seconds. It is very unlikely that for the majority of the subjects in the investigation, children of 11-14 years old, the conditions would be as he claimed, namely, that the tests would be worked under different attitudes to speed. It rather seems that what would happen, would be, that the fastest subjects might be penalised in the "Leisure" tests by having no further work to do, but the majority, or, at least a large fraction, who would not finish either 
test in the thirty seconds would be working both tests under equal conditions, "all-out" in both cases. Hence the L $-\mathrm{H}$ measures for them would be random values. At least, it seems that this is a possibility when it is remembered that in the "Leisure" completion test, referred to above, about eighty words had to be read and understood, and then eight words had to be entered, all in the time allowance of thirty seconds. One supposes that the object of the "Leisure" tests is to provide a test wherein the slower subjects have time to exhaust their abilities. From the structure of these tests it hardly appears that the attitude in the work will be one of "Leisure".

\section{A TEST OF THE VALIDITY OF BERNSTEIN'S METHOD.}

To test this point, some of these tests (published in his monograph) were given to a group of school children about the same age as those used by Bernstein, and to a University graduate. The latter worked through seven of the "Leisure" tests as quickly as he could and his average time was $26 \cdot 3$ seconds! The children, numbering 36 , and of average age about 12 years, formed the "control" class in the one public school of a small town. (The"control"class is the high est class in the primary division of the school, the pupils passing from this class to the Secondary School or Advanced Division). Scoring the tests according to Bernstein's directions, the following results were obtained. The $I$ and $H$ values correlated with the teacher's estimate of intelligence .68 and .58 respectively, and with each other $\cdot 58$. The I - H values, however, formed a normal distribution about zero, uncorrelated with any other measure. That is, as many children failed to add to their score under the "Leisure" 
conditions as increased it, whereas most of them should have increased it. More important, not one child "finished", that is, exhausted his abilities in, any test in the time limits. The $\mathrm{I}-\mathrm{H}$ values would thus seem to be measures of the variability in the individuals' performances plus an error of measurement. The subjects used could not have been far from nomal in intelligence as there was no selection in the community; but they were not given a standard test. It is possible that, not being used to this sort of work, they were rather upset by the novelty; but this could not have been an important factor since practice tests were given.

To make the tests really "Leisure" ones, the children were given coloured pencils and allowed to do as many more items in the tests as they could. These extended-time scores correlated with the scores obtained in the time limit used by Bernstein, $r=\bullet 85$. With the "Haste" test scores, they correlated 61 , compared with the value . 58 when Bernstein's "Leisure" scores were used. The really "Leisure" scores are thus seen to be measuring practically the same function as was measured by the "Leisure" scores according to Bernstein's time limit.

Had there been a well-defined speed factor we do not think Bernstein's method would have revealed it, because his "Leisure" tests would not have been measures, free from the influence of speed. It seems that Bernstein did not find a factor of quickness because there does not seem to be any, if our results can be taken as an indication. When the measures were made in really "Leisure"conditions, they correlated with teacher's estimates of intelligence $r=.75$. This value was for a pool of all the tests. When all the scores 
under the time limits were pooled, they correlated $r=.77$ with the estimates of intelligence. So the same function seems to be measured whether or not, there is a time limit.

\section{SUMMARY OF THE EVIDENCE ON THE

EXISTENCE OF A SPEED FACTOR IN INTELIIGENT REACTIONS.}

The evidence from previous work on the existence of a speed factor in intelligent reactions, independent of level of intelligence, seems to give no clear proof for or against it. The speed factor measured by Thorndike and his students, also by Walters, Highsmith, and Kennedy, may be an individual difference in speed of 'mental reactions', but it does not mean that some individuals can think, or solve problems quickly, without possessing at the same time a high level of intelligence. Data obtained on a principle such as Bermstein used would have revealed a speed factor in intelligent reactions. His conclusions cannot be taken without further confirmation, however, since his "Leisure" measures do not seem valid measures of the characteristic he intended them to measure, namely, level of intelligence. 


\section{CHAPTER II. (Continued)}

\section{ANALYTICAI DATA REGARDING THE SPEED FACTORS IN INTELIIGENT REACTIONS.}

Analysis of the times taken by subjects in intelligent reaction will be a very valuable method of establishing the existence or non-existence of an independent factor of speed. Knowing the times taken by a group of subjects to do certain tasks requiring intelligence for their solution, we can postulate factors possibly producing these time differences. If any of these factors which are unrelated to level of intelligence, correlate consistently with these times, then we shall have proved the times to be related to a nonintelligent factor. Thus we shall have proved the existence of a speed factor and simultaneously shall obtain information regarding 1ts nature. Popularly it would be said that temperarnental trajts contribute to the time differences, to the relations of such traits to the times could be found. It is to be kept in mind, of course, that these times are obtained when the subjects are working with a very special attitude. In everyday life, temperamental differences and hosts of other factors affect the time taken by an individual to a problem. A test situation will eliminate a great number of these extraneous factors, especially subjective ones. The instructions for a test tend to smooth out these differences in attitude. Indeed, we should not be surprised were temperamental factors to play a negligible role in the time of solving test items in a test situation. There are other factors, however, which might influence the speed of intelligent process. The slowing effect of the inertia of cognitive processes, the factor of perseveration, may be a causal 
factor in the time taken to the test items.

On the other hand, the times in the tasks may be very highly related to intelligence level. This would suggest that the factor of level of intelligence determined these time differences and thus investigation of the time differences would be research upon the nature of the level factor.

\section{A SUGGESTIVE CONSIDERATION OF THE SPEED FACTOR IN INTELLIGENT REACTIONS.}

A very suggestive contribution on these lines was made in 1926 by Peak and Boring (33). These authors stated that for them the time differences in intelligent acts were entirely governed by the intelligence. They held the distinction between "speed" and "power" tests to be only a relative one, for what was a "power" test for one subject might be a "speed" test for another. Since speed was therefore fundamentally related to intelligence they proposed to analyse the speed factor as a means of initiating a direct experimental attack upon the nature of intelligence as the tests test it. They first showed that time differences persisted in the simple items of an intelligence test, by recording the times carsfully which subjects took to do these tests. They then sought to analyse the time differences. "We can see whether we shall find the same individual differences in associative reaction times, in cognitive reaction times, in simple reaction times, in reflex times, and ultimately, if necessary, in the rates of nerve-conduction. If It be argued that we should not expect a difference in the rates of nerve conduction, then we may point out that somewhere in the series of times just listed the time-differences, apparent in the intelli- 
gence test, would disappear, and we should have localized the level of complexity at which the difference in time appears." To their surprise they found the time differences still persisted even in simple reactions to a visual stimulus. Those reaction times correlated with the speed in items (those which all of the five subjects performed correctly) in the intelligence tests, .70 with the Army Alpha, and .90 with the 0tis Advanced. They correlated .90 with the scores made in these tests.

It 'was pointed out, of course, that these results were obtained from only five subjects and would have to be confirmed. Nevertheless, they suggest that "speed of reaction is an important, and probably the most important factor in the individual differences in the intelligent act." The authors conclude that "intelligence assumes in psychology the role of 'power' in mechanics. It would seem to be primarily, although as the tests test it not entirely, mental power ... work done against time." Then, since they had failed to localize the speed factor, they suggest that the rate of conduction of the nervous impulse should be measured in individuals of different intelligence.

\section{PEAK AND BORING'S LOCALIZATION OF THE SPEED DIFFERENCES IN INTELIIGENT REACTIONS UNCONFIRMED BY OTHER WORK.}

This result of Peak and Boring's was not confirmed by some of the earlier findings regarding reaction time, and evidently, reliable confirmation would be the first step before proceeding with their suggestion.

A considerable amount of work had already been done on the relation to intelligence of those processes which Peak and 
Boring suggested as constituents of the intelligent act. Data had been obtained regarding the speed of association, and various reaction speeds, and their relationships with measures of intelligence Some of the results are presented below.

Association Speed: Speed of free association was found by Rusk (39), and Anderson (1) to have little relation to intelligence. The data in both investigations were obtained from over 20 subjects in the first-mentioned, and from nearly 100 subjects in the second one.

Reaction Times and Intelligence: Several investigators had found low positive relationships between speed of reaction and intelligence. Many reports however, denied any positive relationship at all.

In $1894 \mathrm{~J} . \mathrm{A} . G i l b e r t$ (20) reported that "a child's mental ability could be judged by the quickness or the rapidity with which it is able to react". Reaction times were obtained as the median of 10 values, and the results were as follows:

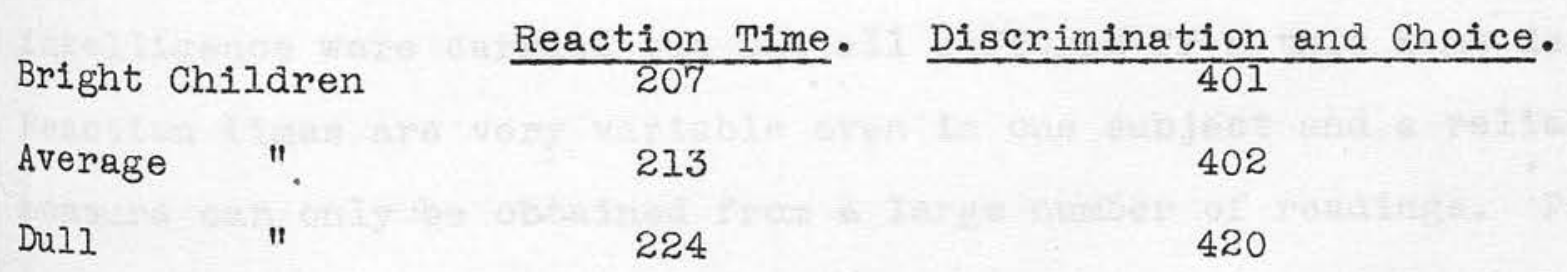

Apparently these differences are scarcely significant statistically. The median of 10 values is, of course, a very unreliable measure and the same may be said of the estimate of brightness (which includes speed of reaction) as $a^{*}$ measure of intelligence. Three years later, Binet and Vaschide (5) found that the intellectual order as obtained from class standing agreed badiy with the order of reaction-times, and Binet (6) confirmed this later. 
Bagley (3) in 1901, however, supported Gilbert's findings, from experiments with large groups of children; but his work suffered from the same defects as Gilbert's. At the same time, and with methods somewhat similar, but using class-standing as a measure of intelligence, Wissler (50) found conclusions opposite to those of Gilbert and Bagley. He found reaction time to be useless as an indicator of mental ability, but little weight can be placed upon his result. The subjects were college freshmen and, with these, average class standings cannot be regarded as a satisfactory estimate of intelligence. In 1904, Whipple (48) reviewed these investigations, and pointed out the spurious nature of the relationships found, on account of the various uncontrolled factors. He maintained that the reaction time was no indication of mental ability, being based on too many variable factors.

The obvious defect in all of these investigations is the unsatisfactory measurement of the reaction time. Other investigations showing that little relationship existed between reaction time and intelligence were carried out but all suffered from this same defect. Reaction times are very variable even in one subject and a reliable measure can only be obtained from a large number of readings. Peak and Boring made 100 observations for each of their subjects thus giving good measures, and against their reliable technique the previous work counts for very little.

Interest in their result produced other data, however, of a high reliability. Farnsworth, Seashore and Tinker (16) measured reaction times similarly, but this time of 35 subjects. They also recorded the times taken by these subjects to solve each item in an 
Intelligence test. From the tests they chose the items performed correctly by all the subjects. These were too few when all the subjects were taken so five groups of seven subjects were made. Within each group, all the subjects had performed a large part of the test correctly in common with the others of that group. The reaction speeds were correlated with these intelligence item speeds. Their results were surprising. The average value from the five groups showed the simple reaction speed to correlate zero with the speed in the test items (and also with the scores in the tests). In the separate groups, however, the values ranged from $-\cdot 66$ to $+\cdot 90$ ! Thus Peak and Boring seemed to have obtained a chance result. According to these three authors, the high result in Peak and Boring's data was aided by the relatively large variability in their subjects. This absence of relationship was further confirmed by Lemmon (29), who found the correlation to be .04 when the results of Thorndike's Examination from nearly 100 students were compared with the reaction times obtained from 40 reactions. The relationship with more complex reactions was also studied by Lemmon. With various degrees of complexity of the stimuli to be discriminated, he found that even with the most complex, there was only a low correlation between intelligence and discrimination speed.

\section{"SERIAL REACTION" SPEED AND INTELIIGENCE.}

In addition to simple reaction speed, many investigators measured "serial reaction" speed, from the time tąken to perform a series of simple reactions successively, the response to one stimulus being followed by a further stimulus. Many varieties of measuring this speed were possible, as most of the common sensori-motor tests 
were employing a process of this nature. Cancellation of symbols and such like processes were used and among the early investigations we have many results reporting the relationships of speeds in cardsorting, tapping etc. The factor of accuracy entered here, of course, but in the simpler processes this was always approximately perfect; and if not, since errors were of the nature of carelessness rather than inability, the time could be "penalised" easily for these mistakes.

Seashore had brought out an instrument in 1902 which was designed to measure serial reaction time. On the presentation of one stimulus, only the correct response brought forth the next stimulus. Times were recorded for the process of working through a given number of stimuli. The instrument was crlled the "psychergograph" since it was intended to measure mental work analogously to the ergograph. This type of apparatus was used by Farnsworth, Seashore, and Tinker in the experiments mentioned before (16) to obtain measures of serial reaction time. They found this to have an appreciable correlation with the performances in the group tests, -30 with the otis Advanced and .53 with the Army Alpha. There was also a low correlation with this time and the speed in the correct items. From these figures they concluded that the Army Alpha emphasized the speed variable with the high intelligences of the University students.

Serial action speed was also measured by Hansen ( 21 ) who remarked on its importance because of the factors it had in common with many processes. such as group tests, which require response to successively discriminated stimuli, "and which have all been studied 
in their possible relationship to intelligence. Speed in such performances was found by Woodworth and Wells to depend on "the maintenance of the proper adjustment throughout the series in opposition to the many interfering tendencies generated by the successive stimuli". Hansen mentioned the various factors, subjective and objective, affecting serial action times and suggests that the degree of attention is the chief determining factor of the time taken (a conclusion which was reached by Burt from similar tests). With a large group of stenographers he got a low positive relationship between scores on the Army Alpha test and the speed of serial action (.14 $\pm \cdot 05$ d. This result rose to $.51 \pm .08$ with a group of music students, which agrees well with the figure of Farnsworth, Seashore and Tinker.

As already stated, speed in processes akin to serial action were much studied by the early investigators. In 1900, Kirkpatrick (2y) found a positive relationship existing between simple motor activities, such as card-sorting, and intelligence as estimated, a result which was confirmed by Aikens, Thorndike and Hubbell (2) and by Binet $(5)$.

The most careful and systematic investigation of this type was that carried out by Burt in 1909 (9). His aim was "to determine whether higher mental functions would show a yet closer connection With 'General Inteliigence' than was shown by simpler mental functions, such as sensory discrimination and motor reaction with which previous investigators had been so largely "engrossed". For this purpose, he obtained an estimate of intelligence from three sources and then correlated this with performances in several tests, 
many of which are of peculiar interest on account of them being largely tests of speed of reaction. The following are taken from his results.

\section{T A B L E V.}

(From Burt's Data).

\begin{tabular}{l|l|c|c|c|c|c|c|c}
\hline $\begin{array}{c}\text { Intelli- } \\
\text { gence } \\
\text { (Estima- } \\
\text { ted). }\end{array}$ & $\begin{array}{c}\text { Dott- } \\
\text { ing. }\end{array}$ & $\begin{array}{c}\text { Alpha- } \\
\text { bet } \\
\text { Sort- } \\
\text { ing. }\end{array}$ & $\begin{array}{c}\text { Card } \\
\text { Sort- } \\
\text { ing. }\end{array}$ & Dealing. & $\begin{array}{c}\text { Mirror } \\
\text { Tachis- } \\
\text { toscope }\end{array}$ & $\begin{array}{c}\text { Draw- } \\
\text { ing. }\end{array}$ & Memory• & Tapping. \\
\hline 30 boys & .60 & .61 & .52 & .44 & .76 & .67 & .57 & .47 \\
13 boys & .84 & .80 & .56 & .29 & .75 & .54 & .78 & .43 \\
\hline
\end{tabular}

That these are chiefly tests of speed is seen from the method of scoring. For Dotting, the measure used was the fastest speed at which three or fewer omissions were made in 10 seconds on McDougall's Dotting Machine: Alphabet-Sorting was the time to sort out alphabets from a jumbled collection of letters: Card-Sorting, the time to deal a bundle of cards into appropriate places: Dealing, the time to put the cards out without placing them: Tapping, the number of taps in 15 seconds. The Tachistoscope and Memory scores were also to some extent dependent upon speed, for the former was dependent upon the rate of perceiving a pattern exposed for a short time and the latter score was dependent upon the speed of organising 30 disconnected words presented serially.

The test correlating most highly with intelligence is the dotting test, success in which is dependent upon the power of voluntary attention according to Burt. This result is of exceptional interest in connection with the speed factor as analysed by Peak and Boring for here we would seem to have a "pure speed" test, its 
material being of zero intellectual difficulty.

Researches also seeking to obtain the extent of the correlation between simple processes and intelligence were carried out shortly after Burt's work, one by William Brown (7) and one by Wyatt (52); there was also a further experiment of Burt's (10). The results obtained were similar, low positive correlations being shown to exist between the speed measures, such as cancellation and addition and intelligence.

From this array of evidence it seems clear that there is little or no relationship between the so-called "simple" processes and intelligence. The age factor introduces complications into the results in some cases. For example, Farmer (15) found with his older subjects that the correlations between intelligence and such processes as dotting decreased to a negligible value, although Burt had found them to be fairly high with boys. According to Farmer, "the "explanation of this appears to be that motor tests for young children are not really tests of motor capacity but of intelligence, since with a partially developed intelligence it is only the really intelligent children who understand what is required of them in a motor test." While we think this to be an overstatement of the facts, we agree that younger subjects 'put more' into motor-test performances, if one might put it in this fashion. The performance seems to require or to absorb their attention in a degree quite different from that with older subjects.

That these processes have low relationship with intelligence is not surprising. It would have been very surprising, indeed, had they revealed the localization of the speed differences, for the 
intelligent act comprises more than the simple ladder of processes outlined by Peak and Boring. We must consider here, however, some further results.

\section{THE REFLEX SPEED AND INTELLIGENCE.}

Shortly after Peak and Boring remarked that few might take seriously their proposal to go so far down their complexity scale as speed of nerve conduction there appeared an account of an investigation on the relationship between reflex rate and speeds in various mental processes by G.H.Rounds (36). The author stated his problem thus: "Is the latent time in the reflex a criterion of potential quickness in strictly mental reactions?" and in some general considerations summed up the problem in a very complete fashion. Individual differences, in speed of reaction seem to be 'sheer speed differences', so he asks if there is a normal speed level characteristic of the individual, - when will he exhibit it and when will he know he is exhibiting it. In mental reactions, fundamental speed differences exist as shown by the facts of improvability. The initially quick tend to retain their speed rankings even after long practice. Again, intelligence tests bring out speed differences which may be extermal to the 'intelligent' aspect; for example, will the speed aspect in Thorndike's analysisf be estimated separately? Considering what "the content of speed in mental reactions can be" he noted that in most studies perseveration of ideas had been studied as the chief causal factor. But in learned reactions the speed will depend on such factors as facility of language, familiarity with the items etc., plus some inherent speed factor little, or not at all, controlled by the individual. This 
was the factor he thought might be represented by the speed of nervous conduction. Individuals might exhibit wide variation in the speed of learned reactions because of the differences in the degrees of learning, which differences may be independent of'native quickness'. Hence his problems: "does the nervous system of the individual exhibit a native quickness of activity?" and, "to what extent does this native speed differ in different individuals?" The latent time in a sample part of the nervous system might be a criterion of this potential quickness and as his sample he chose the Achilles Tendon reflex.

The fact that the unlike structural and functional differences might make the comparison improper, when the possibility was tested by a measure from speed tests and of the latent time, was granted. As the author remarked, 'the purely mental factors such as volition, incentive, and foresight coming between the terminus of the optic nerve fibre in the visual area and the reaction set up in the motor area, bring in a tremendous complexity of variables, but the comparison at any rate seemed worth while.

In his actual experiment, the reflex latency was measured myographically as the period elapsing between the stimulation of the tendon and the initiation of the reflex contraction of the gastroc:nemius muscle. The values obtained from about 80 students ranged from 32-97 $\sigma$ with a mean at $53 \cdot 2 \sigma$. They showed a distribution slightly asymmetrical, there being a heap to the quick end. 40 readings were taken from each subject.

The measure of mental speed was obtained from seven tests including word-association, sentence completion, addition and figure 
xo tests. All the tests correlated positively with the reflex speed. With the addition, figure $\mathrm{XO}$, and completion tests combined, the value of $r$ was $\cdot 59 \pm \cdot 026$, a result which permitted of no doubt as to an existing relationship.

The relative importance of the physical speed mechanism and the uncontrolled mental factors was discussed. Of the totality of factors making up both speed measures the physical and the mental speeds, some would be common to both, viz., the stmuctural and functional physical factors. The letter, according to the author, would be chiefly responsible for the time of a single stroke of attention e.g. crossing out a figure, or an element of addition. Mental factors centred in (1) Accomplishments, purposes, ends, and (2), means for achieving ends. The means would perhaps be the chief factors in the time differences of complex actions. Here, the speed would be proportional to the number of steps taken in achieving the desired result, and to the value of each step in relation to the desired end. For instance, in addition, the number of reactions would be reduced the more there was taken in, in one reaction. The durational pause would also affect the speed. Span of apprehension, it was to be noted, would not be an important factor in such reactions of its own accord. Although four digits were perceived in one stroke of attention, if they had to be added separately by revival the process would be no quicker than one where only two digits were so perceived but were added in this stroke; and this learned ability might be quite independent of span of apprehension. This, of course, raised the question as to how the relationship would change if the subjects were practised in the test material. Rounds said little 
change would occur, on the grounds that improvability had been shown to be proportional to original nature.

With complex processes he pointed out that the comparison of speeds in these with the latency would not be very enlightening. It would be like comparing the latencies with the times taken by bricklayers to lay one brick where one individual used three movements, another five and so on up to much larger numbers. The relation of his result to a general speed capacity was more probable. Such a general speed factor would consist of two more or less independent factors,

(1) the intrinsic physical speed mechanisms centering chiefly in the velocity of nerve conduction.

(2) various mental factors not concerned with transmission of stimuli, defects in the amount and quality of the learning being the chief disturbing factors.

TRAVIS AND HUNTER'S RESUITS ON REFLEXES AND INTELIIGENCE.

Before considering these result's it will be better to study the other results on this question and then take them together. Rounds' result was followed in 1928 by the report of an experiment on "The Relation between Intelligence and Reflex Conduction Rate" by Travis and Hunter (44). They had noticed Peak and Boring's remarks and had also observed themselves an apparent relationship between Reflex speed and Intelligence so they proceeded to verify this with astonishing results. Reflex latency they measured from the time elapsing between the instant of stimulating the patellar tendon and the arrival of the action current at the fipstivg two electrodes placed over the executant muscle. At leas (eight) 
were obtained from each subject, these being recorded photographically. Two groups of subjects were used,

(1) 44 men and women (including types from graduates to farm hands)

(2) 43 University Freshmen.

The first group took the otis higher examination and the second group, the Iowa qualifying test. For group I. the correlation between reflex speed and intelligence test score was $\cdot 87 \pm \cdot 024$, and for group II. the value was the same, showing that heterogeneity in the first group was not the source if the high relationship. Each group gave a fairly normal distribution of reflex times. These, of course, from the different method employed were of a different order from those of Rounds, their range being from $11.4 \sigma$ to $26 \cdot 8 \sigma$. A rough test of the reliability was taken by having another person reread the records from 15 subjects, when nearly perfect agreement was found between the two readings. From their results, Travis and Hunter concluded that the general rate of conduction of the nervous system was important in intelligent responses. It would afford a "neuro-physiological envisagement of the g factor". Their explanation of how it would be important in complex actions like the intelligent act is interesting, especially after Rounds conclusions. It would be important, they thought, "because the more of the nervous system (especially in the higher centers) that is active within a given interval of time the more likely is there to be an adequate response to a complex situation."

These results were undoubtedly surprising and they appeared to be quite reliable. It seemed as if the speed factor lassuming the high relationship between speed in intelligent acts 
and the scores on the tests) was a really fundamental individual difference. So promising was this result, that it must first be established beyond all doubt before the very interesting material was elaborately interpreted.

But the astonishing relationship was followed by a more astonishing one in 1930, in a further report by Travis, assisted this time by Young (45). Setting out to verify the relationship previously found, and finding this to be probably in error, they then sought,

"(1) To discover whether or not the present methods of recording reflex times are sufficiently reliable to make the results of this and of similar studies dependable.

(2) To study the relationship between reflex times and measures of height, length of leg, and length of thigh.

(3) To make a final determination as to whether or not there is any relationship between reflex times and intelligences". Records from over 100 university students were obtained for both the Patellar and the Achilles reflexes. The two reflexes correlated to the extent of $r=.789 \neq .043$ indicating the latencies to be dependent on the same or correlated factors. Patellar records were also obtained from 475 th and 6 th grade pupils; 47 and and 3 rd grade pupils; and 37 preschool children.

(1) Rigorous tests of reliability were executed. Records were obtained from (a), a group of 6 students on eight different sittings for both reflexes; and (b), a group of 39 students on two sittings for the Achilles reflex only. The reliability coefficients were of the order $.90 \pm \cdot 03$. From the single series of records for the individuals of two large groups the 
the average range in variation was found to be about 1.5. Also, finding the correlation coefficients between the values for the first half and the second half of the series of readings to be over .9 , the method was shown to be reliable. Moreover, re-readings of the data with no knowledge of the previous ones gave a reliability coefficient of over $\cdot 9$.

Regarding (2), high relationships were found between the physical measures and the reflex times for all groups, averaging $\cdot 62$ for height and patellar reflex, while the average for the two reflexes and length of thigh for the student group was $\cdot 72$.

These relationships were high, and, considering the reliabilities of the measures, probably indicated that for most Individuals the rate of conduction is constant, the differentiation of the times being almost entirely a function of the length of arc.

(3). Entire absence of relationship between reflex times and intelligence as measured by the tests was found for all the groups, contrary to the previous finding, and even when height was partialled out. And the same evidence denied any relation between speeds in nervous conduction and intelligence.

Naturally one would expect some explanation of the great discrepancy between this finding and the previous one. The records of one of the groups in the first investigation were re-read, "without knowledge concerning the persons on whom they had been secured. The reading of these records revealed the fact that it was much more difficult to get a positive reading of the reflex time on them than on the oscillograph records. The readers were not at all sure of many of their judgments. Reflex times on 28 of the 
individuals, however, seemed fairly certain. These were put in a separate group .... the correlations of these readings with Entrance Examination scores and with the readings on the basis of which correlations with intelligence had been reported" .. were •043 士 .108 and $.489 \pm .096$ respectively. "The discrepancy between our results and those reported in the preliminary study is apparently due to the fact that the records of reflex time secured in the former study could not be read with sufficient accuracy to secure reliable results".

With over 40 subjects, one would have thought that the possible errors in reading would have reduced any relationship. To reduce a relationship of $\cdot 87 \pm \cdot 024$ to one of zero at one re-reading is unusual. Such gross errors must have been revealed even by a simple test of reliability.

of Rounds' result Travis remarked that Rounds used an entirely different measure "not at all comparable to the one herein reported ... and there is no reason for supposing that the two measures would be highly correlated". Also, his relationship was with speed tests which "would not be likely to show much correlation with intelligence".

The complete negation by Travis of the relationship must be accepted in spite of Rounds' result (which has remained unconfirmed for the latter's technique is questionable.

CONCLUSIONS REGARDING THE EXISTENCE OF A SPEED FACTOR IN INTELIIGENT REACTIONS FRON THE ANALYTTCAL DATA.

The speed differences in the intelligent act would therefore seem to be "intelligent" since they have not been revealed nor 
localized in any non-intelligent factors, at least of a cognitive nature. A speed factor of a temperamental origin still remains a relatively unexplored field. In Webo's investigation, quickness of apprehension was correlated with certain temperamental traits more than profoundness was; it had also the highest relationship with "g". But estinates of this kind are not very helpful in this problem because of the difficulty of separating the two factors, intelligence and temperament, in observation. Perseveration was shown by Bernstein not to be a general cause of slowness although it might be a factor in individual cases. Hence from the analytical data there has been established no group factor of speed in intelligent reactions. The specific correlation existing between the usual speed tests has been identified with a group speed factor, a pure 'rate of work', but whatever the interpretation of this be, it has, little influence upon the times taken in reactions requiring intelligence. 


\section{CHAPTER III.}

PRESENT INVESTIGATION: AIMS AND PRINCIPIES DIRECTING

THE EXPERIMENTS.

\section{AIMS.}

As mentioned in the preface, the original aim of the present work was primarily to confirm the high relationship between reflex speed and intelligence announced by Travis and Hunter in 1928. Along with this, there were, of course, other problems which could be studied concurrently. With the publication of the second report, negativing completely the original results, we left this problem. The excellent technique employed by these authors could not be bettered not even equalled, by the cheaper methods we proposed to use. In any case the precautions taken and actual reliabilities of the measures seemed now to be entirely satisfactory. The initial work on the reflexes has therefore been separated, along with some immediately allied work, and appended in a separate section; for although losing interest regarding the speed factor, the material obtained may be of some interest in other connections.

The main inquiry now took up the other problems, the chief of which have been indicated. On the three questions considered we have seen what has been done already. The merely practical question of extending the time limits in the tests has been satisfactorily answered. But with regard to the second and thind problems, the existence and nature of a group factor of speed, the evidence is exceedingly conflicting. The various investigators have reached conclusions flatly contradictory. 
It seems that this contradiction is only apparent, however. Differences in the conception of the speed factor, and consequently of the methods of detecting it, have been the source of this trouble. We have seid that we do not think that the measures obtained by the usual speed tests will reveal a speed factor in intelligent reactions because the more intelligent processes are eliminated in these. At least, their operation is reduced to a minimum. A speed factor in reactions of sufficient complexity to require intelligence as ordinarily understood is the 'quickness' generally spoken of as existing independently of level of intelligence. The principle of Bernstein's method seems to be a satisfactory method of revealing such a factor. Scores obtained in intelligence tests under (I), haste conditions, and (2), leisure conditions, would not correlate equally with other reliable criteria of intelligence if there were a speed factor affecting the scores in the haste conditions. However, his actual data do not appear to be so satisfactory. His method is evidently the same as that used by Walters, when the scores in speeded, and no-time-limit, conditions were compared with other criteria. It will be remembered that the correlations in this case were practically identical, thus showing that no large speed factor affected the scores made in the time-limited conditions. Since certain minor objections exist to the acceptance of these data, e.g. the speeded conditions might not always have been really such for a few good subjects, it was thought advisable to use another method which would show without doubt, the existence or non-existence of a factor of speed in intelligent reactions. Again, since the analysis of the speed differences in these reactions by Peak and Boring was negatived, 
some method of obtaining data on the nature of the speed differences in the intelligent item was sought.

Two problems therefore formed the aim of our experiments.

These were:

1. The obtaining of crucial evidence regarding the existence of a factor of speed in intelligent reactions:

2. Can the nature of these speed differences in intelligent acts be discovered?

The two problems are, of course, really aspects of the one general problem - speed in intelligent reactions.

\section{PRINCIPLES DIRECTING THE ATIEMPTS TO ANSWER THESE PROBLEMS.}

PROBLEM I. A CRUCIAI TEST FOR THE EXISTENCE OF A SPEED FACTOR.

From our conception of the factor of quickness outlined in

Chapter I, the crucial method of establishing the existence, or otherwise, of a factor of speed in intelligent reactions, we think to be as follows. Iet a group of individuals solve a variety of problems, all the subjects giving their concentrated attention to these. The attitude of the subjects is to be one of trying to obtain perfect accuracy in as little time as possible. Also, let these tasks be of such difficulty that the whole group will succeed with them, and let the times taken by the subjects to solve each of these tasks be recorded. A measure of level is also to be taken from all the subjects.

We expect that the times (or composite time measures) will correlate with each other to some extent, because they are each partly dependent upon level. The important matter is whether or not they still correlate when the influence of the level factor has been 
removed by partial correlation. The magnitude of these partial correlations between the time measures will settle in a decisive fashion the question of the existence of a quickness of intelligence apart from level.

PROBLEM 2. CAN WE ANATYSE THE SPEED DIFFERENCES?

In addition to the statistical evidence on the existence of the speed factor will be the evidence obtained from analytical methods. If we can isolate the factors causing the speed differences we shall obviously confirm and explain the result reached from the previous data.

We have a large number of possible factors causing the speed differences in intelligent acts. Previous work has shown, however, that speeds in 'simple' processes, thought to be constituent parts of the intelligent act, are practically unrelated to the speed in this latter. In any case, this method of approach has the fault that it assumes the intelligent act to be a relatively simple aggregate of these 'simple' processes. The speed differences are sought in constituents which are by nature unintelligent.

It seems to us far more likely that the speed in the highly complex intelligent act will be dependent upon different factors entirely. The goal in a problem situation is generally reached after a succession of steps; after a number of eductions of relations and correlates in Spearman's terminology. A step will thus be simple only in the sense that it is a part of a more complex series; in itself it will be of a definitely intelligent character. If we have a group of subjects all successful with certain problems then time differences will be due to two factors. Firstly, certain subjects Will take more steps than others, and secondly, certain subjects. 
may make their steps far more quickly than others. Differences in time due to the number of steps taken would be differences caused by the intelligence factor. To be able to make relatively few steps in reaching the goal of the problem situation indicates a high ability to combine or synthesize the elements of the situation; and this is one of the chief implications of a level of intelligence measure. on the other hand, differences in the speed at which the steps are made may be quite independent of this level factor.

An important type of data would evidently be obtained if the number of steps made by each individual in solving the problem could be recorded along with the record of the time taken. If the correlation between the number of steps and the time taken turned out to be high, the obvious conclusion would be that individuals did not make steps at a widely different rate but that they made these at nearly equal speeds. Subjects of poor intelligence however would take more time because they required to take the solution in simpler stages. Should this correlation be low, it will show that certain individuals may make the same number of steps in solving the problem but take quite different times to these. And hence analysis of the speed factor would have to go into the single step. Peak and Boring sought to do this, having found that speed differences persisted in the simplest of the test problems. But although these problems were of the simplest nature there was no justification for the assumption that they took place by what we might term 'one quantum of intelligence'. There are steps which are still of an intelligent character in the simplest of test problems, e.g., A correlate is not educed without the previous eduction of the relation in the simplest 
of analogies.

Two difficulties would arise in an attempt to gather data of this character. Firstly, it is not usually possible to observe the steps taken by the subject in solving a problem. Secondly, supposing one could observe these, the different character of the steps made by two individuals may make comparisons invalid, for the following reason. In attaining the solution three steps might be made by each subject but in very different times. Can one say on this account that one is slower than the other in the constituent processes? Apparently not, unless we know that these are similar steps. One subject may approach the solution from a different point of view, and unless we know that the critical steps in the problem are similar we cannot really compare the times.

A method of overcoming both these difficulties must be sought if we are to obtain these very important data.

\section{PROPOSED ANALYSIS BY THE USE OF PERFORMANCE TES'IS.}

It seemed to us that certain performance tests of intelligence offered an approximation to a method of observing and recording the steps in the solution of a problem. With subjects of not too high a level of intelligence, the steps in these problems are generally made by means of the concrete material; and the same critical steps have to be made because the elements are provided from which the solution is to be evolved.

\section{DATA FROM IEMPERANENT 'IES'I'S.}

From the implication of temperamental factors in the socalled slow, deliberate and quick, rash, types, it was thought that 
measures of temperamental traits should be compared with the times taken to solve problems. We have observed already that although these traits might be very much in effect in ordinary life, they tend to be eliminated in test situations because of the uniformity of attitude produced by the instructions for the tests. However, it is possible that these traits may not be easily suppressed and it was deemed worth while to make measures of these and compare them with the speeds. Temperament is, of course, a difficult characteristic to assess, but assuming such measuring instruments as we already possess, e.g., the June Downey Will-Temperament Tests, to have some validity and reliability, we could use these. If a relation was found between any of the temperamental traits and the times in the intelligence tests we shall have detected a factor of speed. The relationship would require to be shown to be independent of inteliigence, of course, because it has been shown that some of the temperament tests include this factor when used with certain subjects.

Having thus outlined the principles on which we intend to obtain our evidence, we can now outline the general scheme of inquiry.

\section{SCHEME OF IHE EXPERIMENTS.}

Our data and considerations on these fall into two main sections.

I. The existence of a Speed Factor in Intelligent Reactions.

(a) Several simple tasks from intelligence tests were solved by subjects and the times taken to these were recorded. Measures of level of intelligence were also obtained. The intercorrelations of these times were then examined when the influence of the level factor had been removed by the method 
of partial correlation.

(b) Simple test items were solved under speeded conditions, i.e., the subjects did as many tasks as possible in a given time. The scores obtained on various tests under these conditions were interrelated and examined for the presence of correlation not due to the intelligence level factor.

(c) Some speed tests of the usual very low difficulty type were inter-correlated and examined as before by the method of partialling out the level factor.

(d) Ihe data in the previous sections were examined for the existence of a speed factor independent of level of intelligence. Since intelligence is now often interpreted in a wider sense as the "general factor", we have examined all the previous data f'or a group factor of speed in the Spearman sense, i.e., a factor of speed independent of " $g$ ".

\section{Analytical Data.}

(a) The number of steps taken in certain performance tests was recorded as well as the time. 'l'he correlation between steps and time taken was calculated to see to what extent the time in the tests was governed by the number of steps required. (b) Certain temperamental traits, as measured by the June Downey Tests, were compared with the rate of work in intelligence tests The actual results are presented under these classes in the following chapter. 


\section{CHAPTER IV. \\ METHODS and RESUITS. \\ I (a)}

STATISTICAL EVIDENCE ON THE SPEED FACTOR IN INTELLIGENT REACTIONS FROM THE INTERCORRELATIONS OF THE TIMES TAKEN TO SOLVE SIMPLE PROBIEIS.

The general scheme underlying the data gathered in this section has just been outlined. It is as follows:-

I. A series of simple performance tests were given to the subjects and the times taken to do these recorded. The instructions for these tests were 'to do them as well as they could'. Because of the peculiar effect upon these tests of instructions to hurry, these cannot be given. This does not mean, of course, that the subjects choose any speed over a wide range. They are asked to do their best and maximum effort is thus being used. Moreover the experimenter's stop-watch gives the suggestion of not wasting time but of working brightly without getting speed at the expense of accuracy. Under an attitude like this we should expect speed differences to be manifested clearly.

From the tasks done, only these answered correctly by all, were taken for further consideration. The series so obtained, consisting of nine tests, was then divided into three groups of tests, and the times for each of the tests in one group were "weighted" and combined to give a measure representing the time taken to that group of tests. The total intercorrelations of these three composite measures were tabulated.

Measures of level of intelligence were obtained from (a), a linguistic test, and (b), the Drever-Collins Performance Tests. 
The relationships between these measures and the time measures were obtained, and then the partial correlations between the times when the level was rendered constant. Subjects:

The subjects from whom these data were got formed two groups Group I. A preliminary trial of results and methods was carried out on a group of 36 boys, inmates of an Industrial School, of average age about 13 years.

Group II. Certain data from Group I, of the character described above, were extended by results from a group of nearly 200 youths, inmates of a Borstal Institution. The average age here was about 18 jears.

These groups were far from being "unselected". Since each had a fair range of ability, however, this was not a drawback for our particular purpose. Details of the characters of the groups are given along with the data from each.

The Several Measures:

From Group I:

All of the measures obtained from this group were male by individual testing. At this school the boys were boarded, most of them coming from unsatisfactory homes or having been in trouble of some sort either with the public or the school authorities. But although many of them were thus sent to the school as a disciplinary training, the atmosphere was distinctly free. Indeed, the whole behaviour of the boys was admirable, keen and courteous throughaut the testing. The school sickroom being empty during this period (a sufficient testimonial) we were enabled to use this for all the 
work, thus having no distraction. Mr.Robertson assisted throughout the work with this group, his help being invaluable because of the saving of time and the added convenience in getting the other measures taken in connection with the reflexes (Appendix).

Level of Intelligence: This was measured by the Herring Revision of the Binet Scale and by the Drever-Collins Performance Tests. The latter gave a valuable supplementary measure to the former which is admittedly of a rather abstract and linguistic type; this was especially useful with the subjects of this group as many of them had irregular schooling. The Performance tests were also used for the reason mentioned before, namely, that by these tests we hoped to count the steps made in the process of solving the simpler tasks, these being the easier tests in this scale. The tests were therefore given according to the usual procedure, as described in the book accompanying the tests (14), except for the recording of the additional data. For the level measure the scores obtained in the tests, other than those timed, were used. (Normally the total score is converted to mental age).

Times: As mentioned before, the tasks chosen for the times taken were the simpler tasks of the Drever-Collins Performance Tests. In addition to the usual procedure in these tests, the times taken to solve the separate problems were recorded. (Also the number of moves butthis will be described later). When the subject went beyond the time allowed for credit according to the scale the record was not kept; but few subjects were eliminated from the easier tests "by this restriction, for the standard limits are of a generous nature. Nine tests were obtained from the series which were 
completed successfully by nearly all the subjects within the prescribed limits. These were divided into three groups, to which they belong in the scale. (1), Four were from the Kohs' Block-Design Test, being the second, third, fourth and fifth of the tests in the Drever-Gollins Series; all of these tests use only four blocks. (In this test, coloured designs are presented to the subject who has to build up a replica with cubes painted in different colours on the six sides. The complexity of the design depends on the peculiar arrangement of the pattern, and is also increased by adding to the number of blocks required to reproduce it. The Drever-Collins Tests use ten of Kohs? original series, the first five being four-block designs, the others increasing until 16 blocks are required). (2), Three were of the form-board type of test, namely, the Profile Test, where the parts of a dissected profile have to be assembled correctly, and the two well-known Two-Figure, and Healy A, formboards. In the normal use of the complete tests, the three formboards are credited according to the time taken, but the maximum time limits for the smallest credit, five minutes for each test, were used as the limits in this case. (3), The last two were the first two tests of the Cube Construction Tests, a test somewhat similar to the Block-Design 'Test in that it requires a model to be constructed from painted cubes.

Reliabilities of the Measures and Results; The Herring Mental Age is known to have a high reliability coefficient. The mean Herring M.A. of the group was 135 months with a standard deviation of \pm 17 months. The mean chronological age was 163 months with a standard deviation of \pm 12 months. With age, the two intelligence measures 
correlated as follows:-

$$
\begin{aligned}
& r_{\text {Herring M.A. and Chron.Age }=\cdot 15} \\
& r_{\text {Performance }} \text { Test score and Chron.Age }=.27 \text {. }
\end{aligned}
$$

These relationships were neglected with this group because of the small numbers, and because of their lowness.

It will be seen that on the Herring test the boys were of the dull type, the mean IQ being 89. As this test is probably not a good indication of their true capecity, because of their irregular training, this result cannot be taken too literally. On the performance tests the mean IQ was just over 100. For these tests there are no direct data on the reliability, but it is highly probable that this is of the order of the other individual intelligence scales. Composite time measures were made from the selected nine easy tests to increase the reliability of the measures and also to increase the number of tests which could be used for this purpose. Since only one or two subjects failed in some of the easier tests it seemed rather unnecessary to neglect these tests for the whole group. By combining a few similar tests, then, if a subject happened to have failed in one, the times in the others made a good measure of his performance in the group. No test was selected unless 30 out of the 36 boys had completed it in the standard time and no composite time measure was used for a boy when he had more than one of the sub-tests in the group unrecorded. With the two cube tests, of course, both times had to be obtained actually. (The group originally had 40 subjects but only 36 fulfilled all the requirements).

The unreliability of the time in a single short test will be granted. As Peak and Boring say, time is a very sensitive 
variable, being affected by all sorts of factors, objective and subjective, such as distraction or fluctuations in concentration and in this case the factor of chance in the solution. Variation in effort affects the speed in cognitive processes considerably, as Wild's results have shown, although it does not influence the measure of level of intelligence. Naturally, wide variations in effort did not occur here since the instructions eliminated these. The combining of the time measures for each subject was done by converting all the actual times into units of semi-interquartile range. When the times in any one test are put into a irequency distribution they form a curve, skewed, as would be expected, to the quick end of the scale because of the limits at this end. With such distributions, deviations from the medion in units of this range are probably the most useful measures for comparison. In each of the three groups of tests, the median of the times (in deviation units) of each separate test was then taken to represent the composite time ranking for that group. In those cases where a sub-test was unrecorded it was taken that the score in this would have been worse than in the others which were recorded. By taking the times less than the median value as positive, quicker speeds were represented by positive scores in deviation units. Although they are actually measures of time, we shall refer to these measures as The Speed Measures in (1) Blocks: (2) FormBoards: (3) Cubes. Negative correlations are thus avoided between level and time measures.

An example will make the combining method clear. Suppose a subject took 10,20, 30, and 25 seconds in the four Block-Design 
Tests. On converting to deviation units these become $+1,+\cdot 8$, $+\cdot 1,+1 \cdot 2$. The median of these last four values is $+\cdot 9$, and this is used as his speed measure for this group. If he had failed to complete number four in the time allowed, the median would have been $+\cdot 5$, since this is the value obtained if the fourth test deviation score is assumed to be slower than all the others. (For a subject taking the full allowance of time, the deviation score corresponding to this limit value was in most cases about -5 . Incidentally, this fact of the limit being five times the semiinterquartile range from the median of the times actually taken shows how ample the limits were).

The reliability of these composite speed measures is probably not very high. When the times taken to the separate tests in a composite are intercorrelated, the average value of the intercorrelations is generally low. Actual values are given for the three composites used, in Table VI. From these average values, the reliability of the composites can be indicated by getting the coefficient from the Spearman-Brown formula for a test $n$ times as long as the sub-tests, where $\mathrm{n}$ is here the number of these subtests in the composite. For example, the average intercorrelation of the four sub-tests of the Block-Designs is $\cdot 23$. The reliability coefficient for a test four times the length of of the sub-tests is .54

\section{TABIE VI.}

INTERCORPELATIONS OF THE TIMES IN THE SEPARATE TESTS OF THE THREE GROUPS FROM WHICH THE COMPOSITES ARE MADE. 


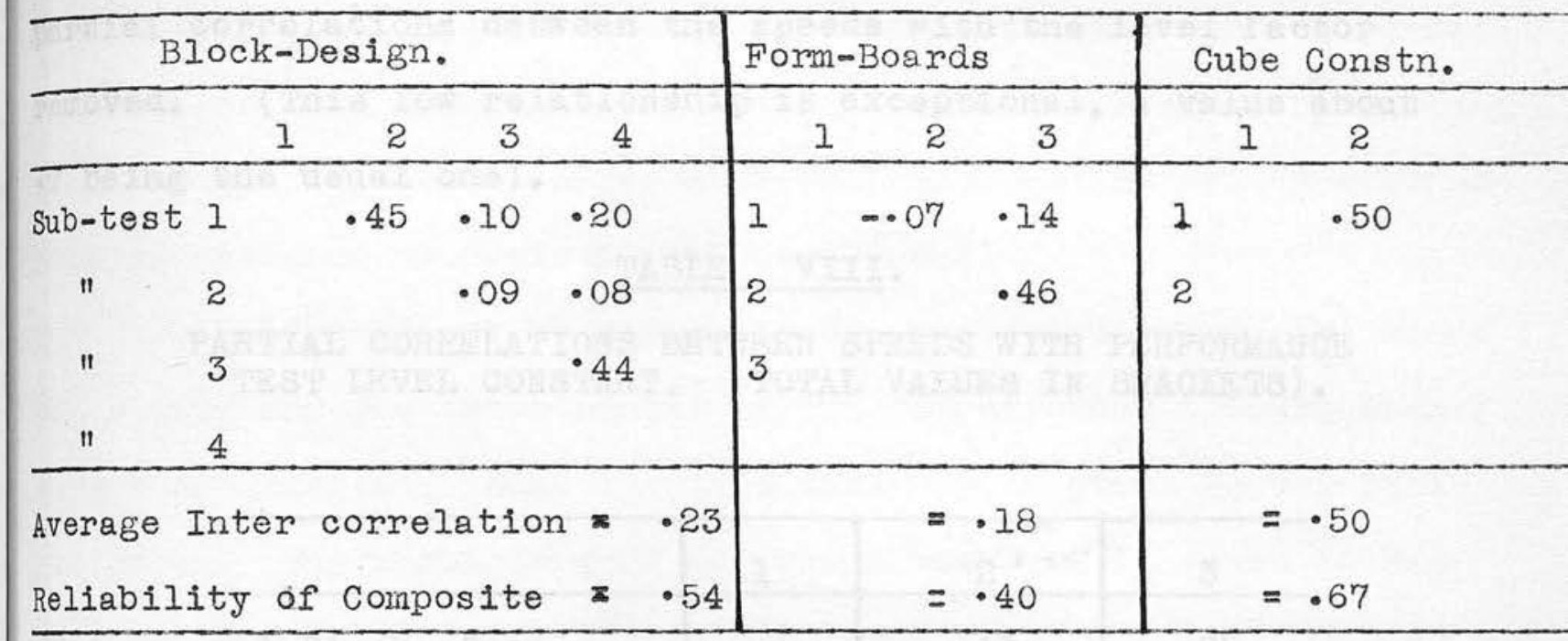

With age, the (composite) speeds in the Blocks, Form-Boards, and Cubes, correlated $r=\cdot 36, \cdot 20$, and .22 respectively. As before, this factor was neglected in this group.

The total correlations between the level and speed measures are now given, followed by the partial correlations between the speeds when the level factor is removed (Tables VII, and VIII.)

\section{TABIE VII.}

TOTAL CORRELATIONS BETWEEN LEVEL MEASURES AND SPEEDS.

\begin{tabular}{|c|c|c|c|c|}
\hline Test. & $1 \quad 2$ & 3 & 4 & 5 \\
\hline 1.Herring M.A. & .47 & $\cdot 23$ & $\cdot 3 I$ & $\cdot 43$ \\
\hline 2.Performance Test Score & & $\cdot 44$ & $\cdot 50$ & .57 \\
\hline 3.Blocks Speed & & & $\cdot 56$ & $\cdot 49$ \\
\hline $\begin{array}{l}\text { 4. Cubes Speed } \\
\text { 5. Form-Board Speed }\end{array}$ & & & & $\cdot 48$ \\
\hline
\end{tabular}

Since the level. measure from the Herring test seemed to have so little in cormon with that from the Performance Test $(r=.47)$ it has been neglected and the latter used alone in determining the 
partial correlations between the speeds with the level factor removed. (This low relationship is exceptional, a value about .7 being the usual one).

\section{TABIE VIII.}

PARTIAL CORRELATIONS BE'IWEEN SPEEDS WITH PERFORMANCE TEST IEVEL CONSTANT. (TOTAL VALUES IN BRACKETS).

\begin{tabular}{l|c|c|c}
\hline & 1 & 2 & 3 \\
\hline 1.Blocks Speed & & .43 & $\cdot 23$ \\
2. Cubes " & $(\cdot 56)$ & & $\cdot 27$ \\
3. Form-board Speed & $(\cdot 49)$ & $(\cdot 48)$ & \\
\hline
\end{tabular}

The partial correlations between the speeds are lower but still positive; before the level factor was removed they were statistically significant, but they now lose this property. Since these data have been extended with Group 2, a large homogeneous group regarding the age factor, there is no need to generalise or interpret them until we have examined the more reliable data. Group II.

The opportunity of extending the previous data on a large scale arose when the inmates of a Borstal Institution were tested as part of an investigation undertaken by Dr.Drever. The youths were given the Drever-Collins Performance 'Tests and the KuhlmannAnderson Group Test. There were thus two measures of level of intelligence as before; a linguistic one from the Group Test and the one from the performance tests. And also as before, the latter provided the simple tasks for which the times were recorded. There 
were nearly 200 subjects and the individual testing for the Performance Tests, and group testing with the other, were done by the staff of the Psychology Department in Edinburgh University with the help of research students in the department.

Although not by any means an unselected group, the range of ability and the large number of subjects afforded a considerable amount of material. Some specific data may be given to describe the group. The chronological age range was from 16 years to $22+$ years with a mean age of 18 years 10 months and $\neq \pm 17$ months. With the group test, which is scored directly in mental age units, the mental age range was from 8 to $15 \frac{1}{2}$ years with a mean at 11 years 10 months. This would make the group appear below normal as whole but the same conditions affect these mental ages as did the Herring mental ages with the boys of Group I, probably to a greater degree as the schooling records showed that education had been for most subjects seriously interrupted. When the performance test scores are considered we get a distribution making the mean intelligence practically normal. The standard deviation of the mental ages from the group test is \pm 21 months, with this value distended by a percentage of defectives slightly higher than usual, there being $6 \%$ below 9 years (Kuhlmann) mental age and $12 \%$ below $9 \frac{1}{2}$ years mental age. The performance test scores also show this slight heaping at the low end. As before, the raw scores in this test were used, exclusive of the tests selected for the speed measures. The mean total raw score on these tests was 104 and since this corresponds to a mental age of 14 years (the highest age norm. $15+$ corresponds to a score of 112) it will be seen how nearly normal the intelligence: 
are by this measure.

Since the chronological age range is large, the possible influence of this factor on the measures was tested, but it was found to have no relationship with either the level or speed measures. The actual values were

$\begin{array}{cll}\text { Chronological Age and Performance Test Score, } & r=.02 \\ \text { " } & \text { " " Kuhlmann Anderson m.a. } & r=.05 \\ \text { " } & \text { "Median of All Speeds. } & r=-.05\end{array}$

The 'median of all the speeds' measure was the median value of the times in all the 9 tests selected as speed measures in the case of Group I.

It was found that, from the total group, 170 cases completed for the most part the same tests as were selected for the previous group. This number could therefore be expected to provide reliable data upon the same questions as were considered before. Composite speed measures were made as before.

The intercorrelations of the separate tests in the composites are given along with the estimated reliabilities of these (cf. Table VI.) from the Spearman-Brown formula.

Results from Group II.

TABIE IX. / 


\section{TABIE IX. (Compare Table V. p.46)}

INTER CORRELATIONS OF THE SPEEDS IN THE SEPARATE 'IES'IS OF THE 'IHREE GROUPS FROM WHICH THE COMPOSITE SPEED SCORES ARE MADE.

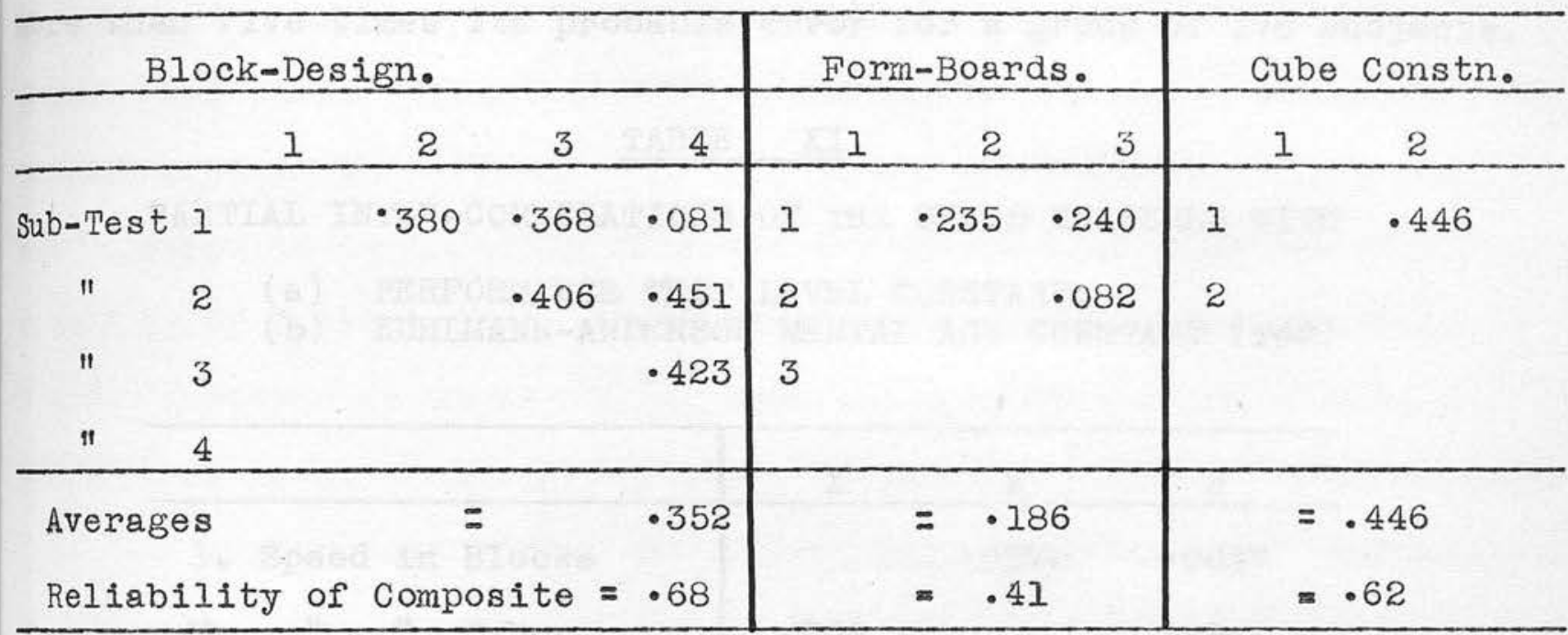

From these results it appears that the Blocks and Cubes Speed measures have fair reliability but that the Form-Boards do not come up to the same standard. Probably this is due to the greater influence of the chance factor in the form-boards which is considered by many psychologists to be serious in tests of this type.

The data on the relationships between the level and speed measures are now presented, followed, as before, by the partial relationships when the level factors are made constant. Both level measures have been used this time since they correlate fairly highly with each other, $r=700$.

TABIE X.

TOTAL INTER-CORRELATIONS BETWEEN LEVEL AND SPEED MEASURES

\begin{tabular}{l|ccccc}
\hline & 1 & 2 & 3 & 4 & 5 \\
\hline 1. Kuhlmann-Anderson m.a. & & .700 & .310 & .541 & .465 \\
2.Performance Test Score & .700 & & .484 & .648 & .609 \\
3. Speed in Blocks & .310 & .484 & & .332 & .332 \\
4. " " " Cubes & .541 & .648 & .332 & & .555 \\
5." "Form-boards & .465 & .609 & .332 & .555 & \\
\hline
\end{tabular}


The probable errors of these coefficients are not entered in the table but it may be noted that a coefficient of $\cdot 250$ is just more than five times its probable error for a group of 170 subjects.

$$
\text { TABIE XI. }
$$

PARTIAL INIER-CORRETATIONS OF IIHE SPEED MEASURES WITH

(a) PERFORMANCE TEST LEVEI CONSTANT.

(b) KUHLMANN-ANDERSON MENTAL AGE CONSTANT (red)

\begin{tabular}{|c|c|c|c|c|}
\hline te & & 1 & 2 & 3 \\
\hline 1. Speed ir & Blocks & & $\cdot 0270$ & - 0547 \\
\hline 2. " " & Cubes & .205 & & $\cdot 266$ \\
\hline 3. " " & Form-boards & .223 & .406 & \\
\hline
\end{tabular}

\section{SIGNIFICANCE OF THE RESULTS.}

These data may now be considered. From Table IX. it will be observed that the total correlations between the speed measures are all significant, the average value being $r=.406$. This relationship is dependent upon two chief factors, level of intelligence and the hypothetical speed factor. In Table XI. the influences of level are removed by two measures, level as measured by the group test and level as measured by the performance test. The results are slightly different. Removing the level of the group test we obtain an average coefficient of correlation between the times of $r=.278$ which is statistically significant. Of this value, however, it may be noted that a large part comes from relationship of the Form-Board test, the most unreliable of the speeds. However, it might be objected that, since the group test is a speeded test, we are 
partly removing the speed factor. If we really have removed a part of the speed factor this relationship is all the more significant. But we have stressed sufficiently the point that we do not think these time-limit tests include a speed factor to any appreciable extent so that the evidence must be taken as it stands, viz., that there seems to be a factor of speed independent of level in the solution of these tests. It is not an important one but it does exist. However we do not think this evidence is satisfactory. The measure of level of the group tests correlates .700 with that obtained from the performance tests, not a very high relationship. Obviously the proper level measure to use is the one obtained in the performance tests. In addition to this probably being a truer picture of these particular subjects' general capacity, it is obtained from the same sort of material used in the timed tests. Although the correlation of $\cdot 700$ with the group test is not notably high, it is as high as the usual relationship between a test of this character and an individual test. The average relationship between group test scores (extended time) and Binet mental ages can be shown from Walters' data to be only $\cdot 599$, and Root (35) from extensive testings showed this value, but for standard times, to be .66 \pm .077 .

It cannot be doubted that the performance test score is a good measure of 'general level'. What must be shown is that it is independent of speed. We have stated that the time limits are of a generous character. But this can be proved by examining the times taken by the subjects in the other tests of the scale, the tests which are making the level measure. 'l'ime limits must be set to any test in practice, but if we can show that for the subjects 
succeding in the tests the distribution of the times shows a central value and scatter well within the limits we cannot but conclude that failure to score is due to lack of ability.

The score we have used as a level measure is made up from five Block-Design tests, possible credit 18 points; three tests where time limits are unimportant, the Knox-Cube l'apping Test, a performance test of memory and a test of weight discrimination, total possible credit 40 points; a fur ther cube-construction test with possible credit of 16 points; and a picture completion test of possible value 18 points. Of these the tests which have time limits are the Block-Design, and the last two. 'l'here are five sub-tests in the Block test with time allowances of 3 minutes for the first two and $3 \frac{1}{2}$ minutes for the others. They are fairly difficult and are only passed by the better subjects. It is generally found that the subjects who make an intelligent performance in these tests finish well within the time. Should a subject be very nearly finished at the time limit, when it is apparent that only a few seconds would be required to complete the test, he would be credited with that test. A subject not finishing within the limit is not likely to complete the test except by the aid of chance which can be very useful in these tests. When it is intelligence we wish to measure we cannot allow an indefinite time to these tests because of this chance factor and the peculiar nature of the tests, which would bring most subjects to a solution after some time. Since the material. with which the solution is obtained is before the subject in concrete form, it is possible to arrive at a solution by trying every unit in all the possible positions, until the model or design is completed. 
Hence, in time, most subjects would succeed with all the tests if they showed mere persistence. But no one would agree that such a success should be ranked as intelligent in the same fashion as the success obtained by inteliigent methods.

The times taken by the subjects who do succeed are illustrative. The distributions of the times in those tests we are using as the speed measures are all of the same character. The peak and greater part of the distribution comes within the given limit and there is a tapering off at the slow end in an indefinite fashion. With the more difficult tests, conditions are slightly different as will be seen from the diagrams. Some of them show the same character as the previous ones but one of the Block Design (No.6) tests shows an increasing frequency of successes up to the time limit, while the others except Number 7 show fairly large frequencies in the last interval. Does this mean that the so-called level measure from these tests includes the speed factor? We do not think so. The times allowed are sufficient if the process of solution still retains the qualities of intelligence, and the judgment of the psychologist must be accepted here. In Kohs' account of his Block Design 'Pests, and his time limits are used here, we find the following statement (28, p.69): "The time limit set for each design is about one minute longer than the time within which a correct response may reasonably be expected."; and this principle has been used with the other performance tests. Moreover Kohs showed his test to correlate, as given, with Stanford Binet $r=.83$ and Porteous (34) has shown some of the other tests used to correlate satisfactorily with this measure. 
81.

DISTRIBUTIONS OF TIMES TAKEN IN THE

PERFORMANCE TESTS

2.
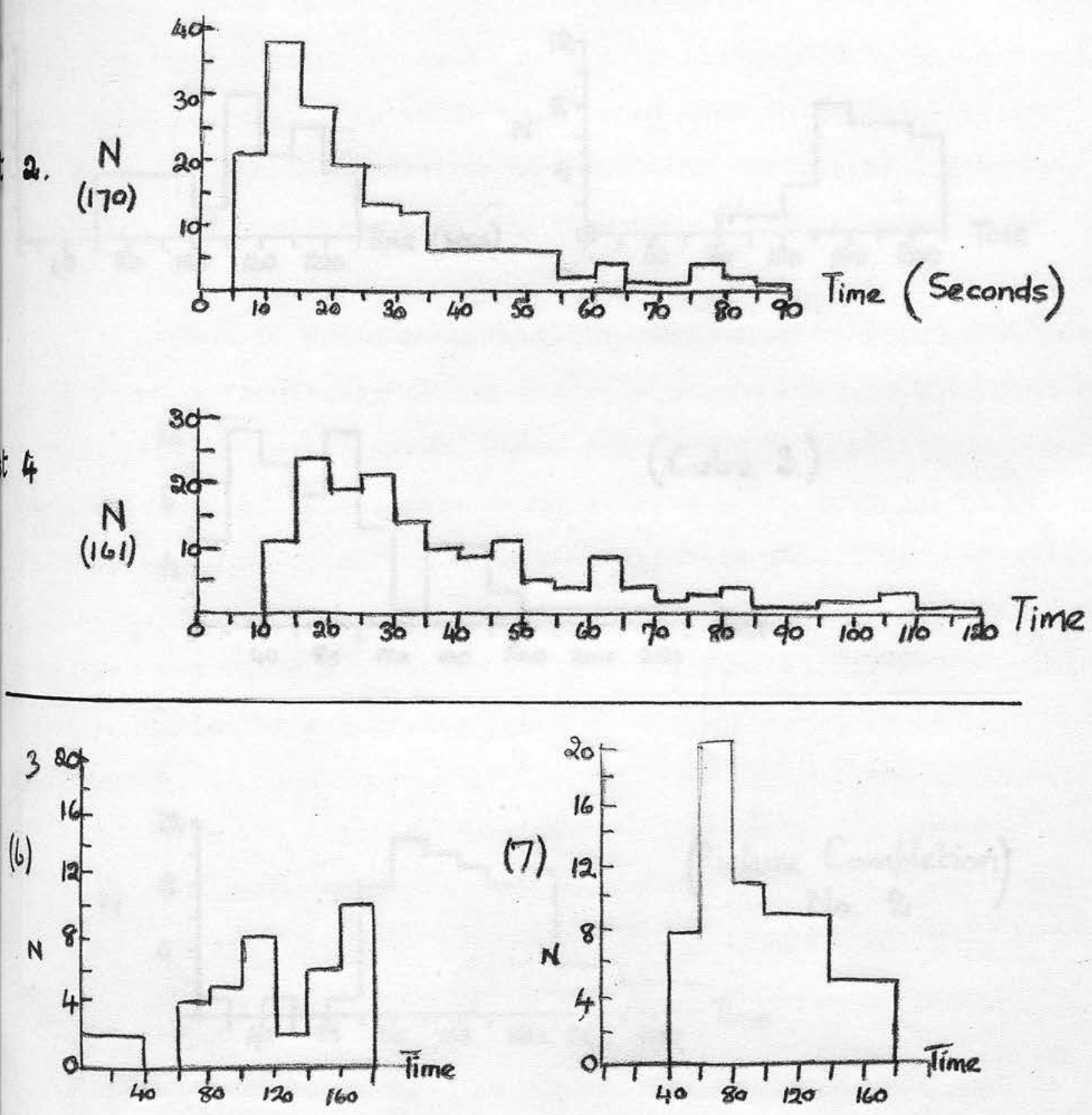

Tests 2 and 3 were completed by most subjects.

Tests 6 and 7 form part of level measure. 
82.

(Contd.)

(8)

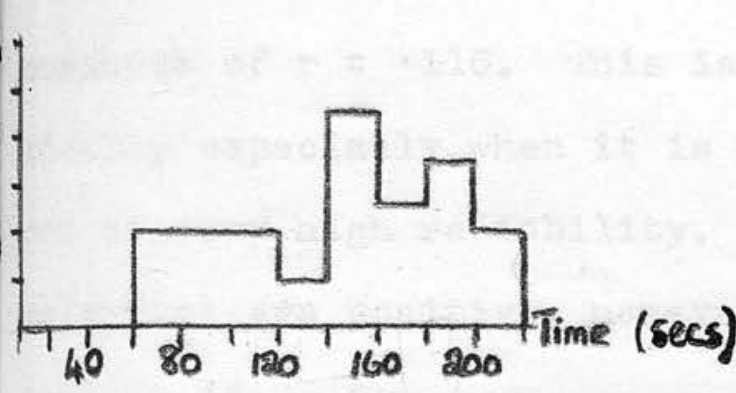

(9)

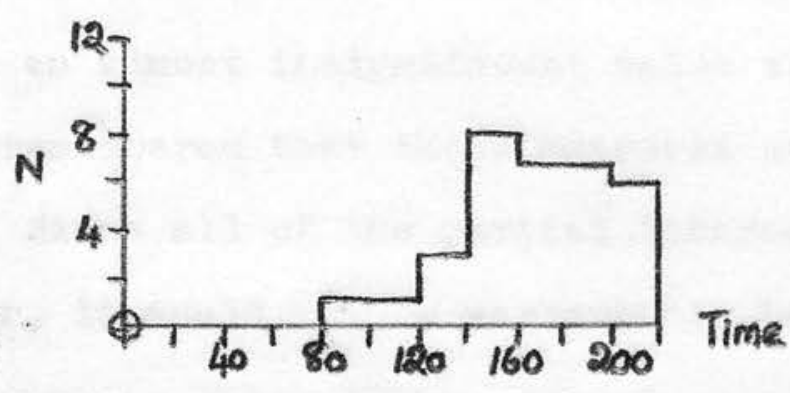

(Curse 3)
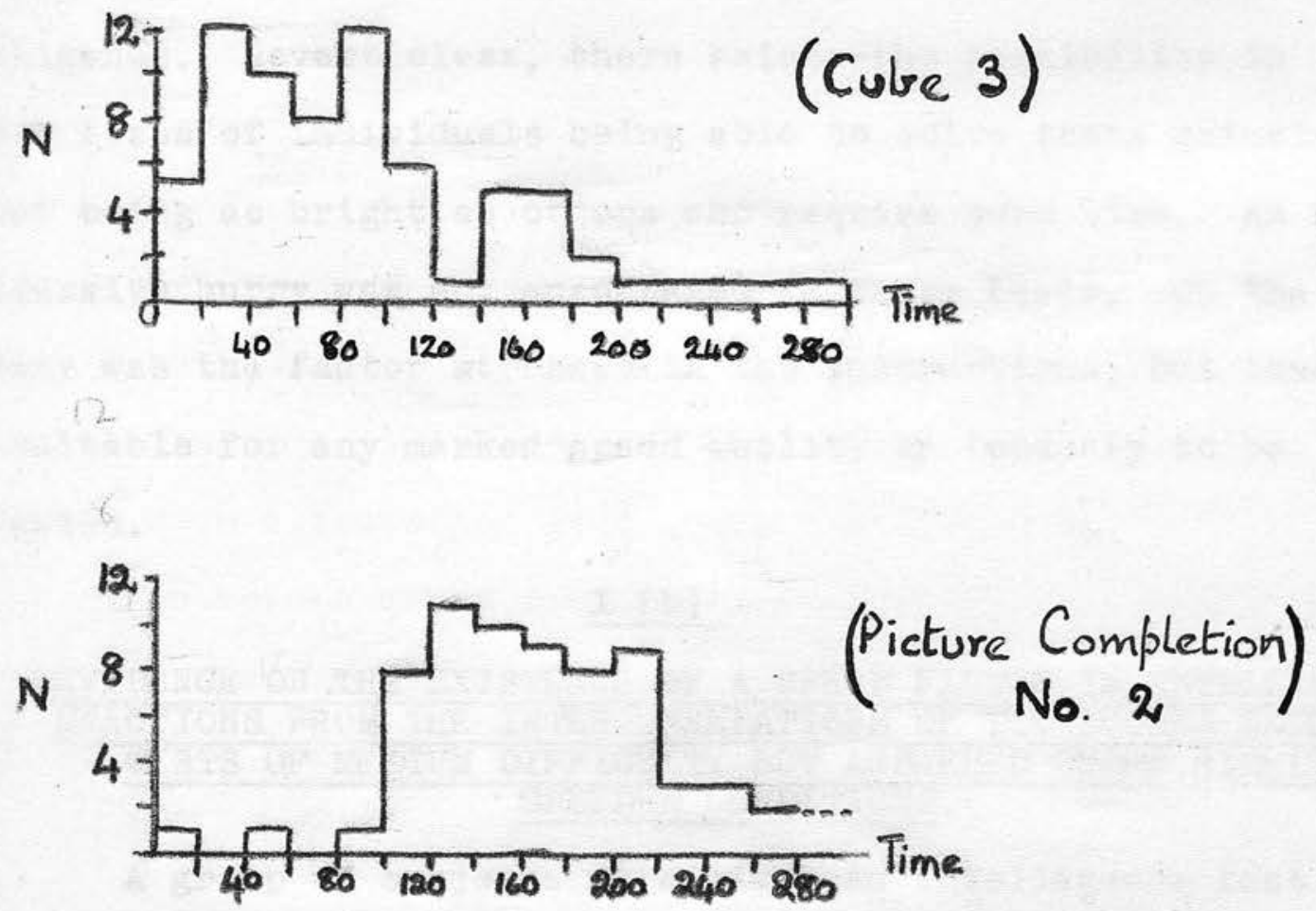

Distributions of times taken in tests forming level measure showing ample nature of the bine - limits. 


\section{CONCLUSIONS FROM THESE DATA.}

Accepting then the performance test score as a valid measure of level of intelligence, we find that on removing its influence, there is an average intercorrelation between the speed measures of $r=\cdot 116$. 'Ihis is an almost insignificant value statistically especially when it is remembered that these measures are not of very high reliability. Since all of the partial intercorrelations are positive, however, it would not be warrantable to neglect it.

Thus it would seem that the time taken to solve problems of medium difficulty is almost entirely dependent upon the level of intelligence. Nevertheless, there exists the possibility in isolated cases of individuals being able to solve tests quickly without being as bright as others who require more time. An attitude of excessive hurry was not encouraged in these tests. On the contrary accuracy was the factor stressed in the instructions, but conditions were suitable for any marked speed ability or tendency to be manifested.

\section{$\underline{I(b)}$}

EVIDENCE ON THE EXISTENCE OF A SPEED FACTOR IN INTELIIGENT REACTIONS FROM THE INIERCORREIATIONS OF THE SCORES MADE IN TESTS OF ME DIUM DIFFICUL'IY BUT ANSWERED UNDER HIGHIY

1 SPEEDED CONDIIIONS.

A group of subjects were given an intelligence test of a medium degree of difficulty for them. The test was such that in ample time all the subjects would have scored practically full points. It was thought that if these tests were done under highly speeded conditions any speed factor would be revealed in the intercorrelations of the sub-test scores. These scores would correlate 
by virtue of the level factor but would also correlate from a speed ability in intelligent reactions if this were present. To test the presence of this factor, the total inter-relations between the subtests were compared with the partial ones obtained by rendering constant the level factor as measured by another test. RESULTS.

The test done under speeded conditions was the National Intelligence Test Form Al, while the level measure was obtained from the Otis Advanced Exan ination Form B.

Subjects: The subjects were taken from a group of students of the Ordinary Psychology Class of Edinburgh University. The student group, Group III, had 86 students, but only 66 of these took part in this experiment.

The Speed Test was given with time limits for each subtest such that no one could finish. The instructions were to work as quickly as possible with perfect accuracy.

(The time limits adopted were determined beforehand by experiment with a few other students.)

The actual score from the number of correct items in each sub-test was used as the measure of speed. Perfect accuracy was thus ensured in the speed measure.

Table XII. gives the total inter-relations of the scores In the sub-tests and of these with the measure of level, while Table XIII. gives the partial inter-relations of the sub-test scores when the otis score is made constant. 


\section{TABLE XII.}

TOTAL INTERCORRELATIONS OF THE NATIONAI SUB-TESTS AND OTIS SCORE.

\begin{tabular}{|c|c|c|c|c|c|c|c|}
\hline & & 1 & 2 & 3 & 4 & 5 & 6 \\
\hline 1. Otis Score & & . & $\cdot 32$ & $\cdot 32$ & $\cdot 24$ & $\cdot 44$ & $\cdot 43$ \\
\hline 2. National & 1 & $\cdot 32$ & & - $4 I$ & $\cdot 25$ & $\cdot 41$ & .00 \\
\hline 3. $11=$ & 2 & $\cdot 32$ & $\cdot 41$ & & $\cdot 34$ & $\cdot 42$ & $\cdot 10$ \\
\hline 4. 11 & 3 & $\cdot 24$ & $\cdot 25$ & $\cdot 34$ & & $\cdot 42$ & -.02 \\
\hline 5. & 4 & $\cdot 44$ & $\cdot 41$ & $\cdot 42$ & $\cdot 42$ & & $\cdot 16$ \\
\hline 6. 11 & 5 & .43 & .00 & $\cdot 10$ & -.02 & $\cdot 16$ & \\
\hline
\end{tabular}

Average Correlation amongst speed tests $=.25$

$"$ of otis Scores and
Speed tests $=.35$
TABIE XIII.

PARTIAL INTERCORREIATIONS OF THE NATIONAL SUB-TESTS, IEVEL RENDERED CONSTANT.

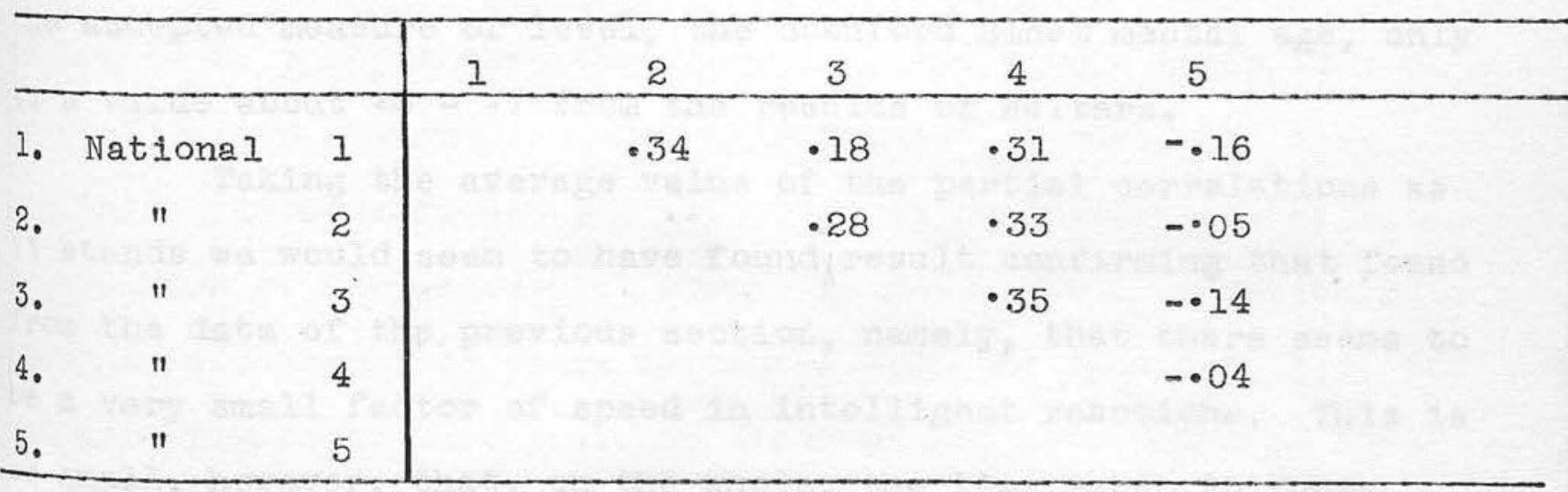

Average Partial Correlation $=\cdot 14$.

SIGNIFICANCE OF PHESE RESUITS.

Before interpreting these results it may be repeated that the otis Test Score has been taken as a valid measure of level practically free from any speed influence. The high relationship 
between the standard and no-time-limit scores is our justification for its use.

From Table XII. it will be seen that the average relationship between the sub-test scores and the level measure (otis score) is actually higher than the average intercorrelation between the speed tests. This is contrary to expectations if a large speed factor determined the scores in the sub-tests.

Table XIII. shows that what we normally call intelifgence is the chief factor in these scores. The average total correlation between the speed tests is .25 but the partial correlations, level rendered constant, have an average value of only 14 . It would be unwise to stress too much the significance of the partial relationships here, however. Although we have assumed the otis score to be a measure little affected by any speed factor it will be remembered that it may not be a very good index of level. It correlated with the accepted measure of level, the Stanford Binet mental age, only to a value about $\cdot 6-.7$ from the results of Walters.

Taking the average value of the partial correlations as

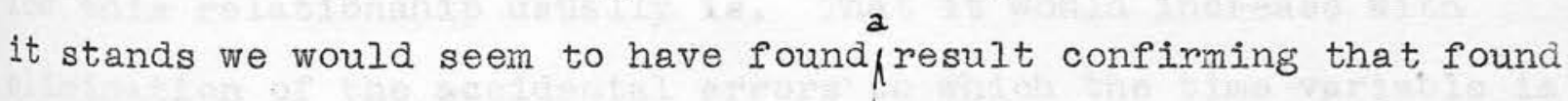
from the data of the previous section, namely, that there seems to be a very small factor of speed in intelligent reactions. This is so sinall, however, that, on the whole, the time taken in these reactions can be said to be governed chiefly by the level of intelligence. This result applies, of course, only when the subjects are giving their maximum effort to the tasks. 


\section{CONCLUSIONS REGARDING THE EXISTENCE OF A SPEED FACTOR IN INTELIIGENT REACTIONS.}

From the results of the last two sections it would seem that Bernstein's result is confimed. Quickness in intelligent reactions is for the most part intelligence as ordinarily understood, 1.e., level of intelligence. We say for the most part since the results do not negative entirely the existence of a speed factor independent of what we have measured as level, but, if this exists, It is the exception rather than the rule. The fact that the partial correlation coefficients between the speeds in the tests, when the level factor is removed, remain constantly positive, although low, suggests that we cannot be dogmatic with individual cases. We must keep in mind that though slow, there is a possible chance that a subject may be bright. The general tendency is contrary to this however.

Because of the non-existence of any large speed factor, it is not to be thought that the times in a few simple tasks will be a good criterion of intelligence. Far from it, for we have seen how low this relationship usually is. That it would increase with elimination of the accidental errors to which the time variable is peculiarly susceptible seems certain. From the data obtained, it was actually found that when the times of all nine tests in the performance tests were made into one composite measure (by the method described previously) this composite measure correlated with the Performance Test score to the extent of . 731 for the subjects of Group II.

For the group doing the National Test, the total score obtained under these speeded conditions correlated with the otis 
soore to $r=.58$.

$$
\text { I (c). }
$$

EVIDENCE REGARDING THE EXISTENCE OF A QUICKNESS IN REACTIONS OF VERY LOW DIFFICULTY: THE SO-CALIED "RATE OF WORK" FACTOR AND ITS REIATIONSHIP TO INTELIIGENCE.

We have said that the 'quickness of mental reaction' spoken of by many psychologists in connection with a speed factor in intelligent reactions would not be very influential in these, since this quickness must be measured in processes of a very low level of difficulty. The proof of the existence of this quickness is the lowness of the relationship between measures from speed tests and measures of intelligence. Actually, however, few investigations have shown conclusively that such a general ability for quickness in these simple processes exists. The essential condition of equal accuracy for all the subjects has not always been observed, while not many reports show the relationships between the speed measures when the intelligence factor is removed. We have obtained measures of speed in a selection of simple tasks to find whether, or not, there is a quickness in these reactions independent of intelligence. RESULTS.

The Subjects were 86 students (Group III.) of the Ordinary Psychology Class.

Measures: The speed tests comprised the following:

(1), Cancellation of particular letters ( $a$ and $e$ ) from mixed continuous type:

(2), Addition of single digits in groups of three:

(3) and (4) Simple Arithmetical Problems and Sentence completions from Thorndike's series. (43).

(5) Passage of Easy Directions from the Woodworth-Wells Association 'l'ests (5I). 
The measures from (1) and (2) were taken as the number of correct responses within the time allowed. In the other three tests, all the subjects finished the tests and recorded the times they had taken to do each. The timing was done by the subjects in a simple fashion. Three sets of large printed numbers, from $0-9$ in each set, were fastened alongside on the edge of a table facing the subjects. Each set was then folded back on to the surface of the table with the exception of the $9 \mathrm{~s}$ these being exposed to view, thus forming the number 999. This number was entered at the beginning of every test in a space provided. The instructions for these tests were to work as quickly as they could, but accurately, and then immediately on finishing to look up and enter the number now showing, again in the space provided. The numbers were changed by one digit every two seconds, this being done easily by releasing a sheet from the bundle. To enable the experimenter to keep a careful watch on the subjects, to ensure all doing what was asked, the changing was done to a metronome, muffled so that it was not heard at a distance. A few practices made the whole procedure very simple both for experimenter and subjects. A check was kept upon the recording, also to provide a test of the reliability, by having the time numbers entered more than once during the test. By changing the numbers from 999 downwards the subtraction of these to obtain the times was facilitated, the larger number being always 'on the top line'. With two of the tasks the times for two sections of the same one correlated .60 and .71 which is satisfactory when it is remembered that the recorded times include variability in performance as well as errors in recording. A disadvantage of this 
procedure is that the quick have to wait quietly for the slow. With student subjects giving very good co-operation in the work this was not the disturbing factor, it might have been.

In the speed tests the accuracy obtained was perfect in the case of the cancellation and the addition since only the number of correct responses within the time limit were counted. The number of errors were very few however. With the other tests there were a few errors, mostly in the Arithmetical Problems. Inaccuracy was penalised by adding to the time taken an amount equal to the average time taken to do one element of the test. Thus a subject performing 39 correctly out of 40 problems in 80 seconds was regarded as having taken 82 seconds. The instructions, however, had sufficiently emphasized that rate was to be accompanied by accuracy, so that this correction was not often required.

The intercorrelations of the speed measures are given in Table XIV. along with the correlations between the speed and intelligence. In Table XV. the influence of the intelligence factor is removed.

\section{TABIE XIV.}

TOTAL CORRELATIONS OF THE SPEEDS AND OTIS SCORE.

\begin{tabular}{|c|c|c|c|c|c|c|}
\hline Test. & 1 & 2 & 3 & 4 & 5 & 6 \\
\hline 1. Otis Score & & .41 & $\cdot 20$ & $\cdot 44$ & .03 & $\cdot 24$ \\
\hline 2. Cancellation & .41 & & $\cdot 22$ & $\cdot 43$ & .11 & .08 \\
\hline 3. Addition & $\cdot 20$ & $\cdot 22$ & & $\cdot 28:$ & $\cdot 20$ & . 41 \\
\hline 4. Directions & $\cdot 44$ & $\cdot 43$ & $\cdot 28$ & & $\cdot 19$ & $\cdot 33$ \\
\hline 5. Sentences & .03 & .11 & $\cdot 20$ & $\cdot 19$ & & .36 \\
\hline 6. Arithmetic & .24 & .08 & .41 & .33 & .36 & \\
\hline Average & between & $\begin{array}{l}\text { otis } \\
\text { Spe }\end{array}$ & $\begin{array}{l}\text { and Speeds } \\
\text { eds }\end{array}$ & $\begin{array}{l}=.27 \\
=.26\end{array}$ & & \\
\hline
\end{tabular}




\section{TABTE XV.}

PARTIAL CORRELATIONS OF THE SPEED MEASURES WI'LH LEVEL (OTIS SCORE) CONSTANT.

(Total values in brackets for comparison).

\begin{tabular}{l|ccccc}
\hline & 1 & 2 & 3 & 4 & 5 \\
\hline 1. Cancellation. & & .16 & .31 & .11 & -.02 \\
2. Addition. & $(.22)$ & & .21 & .19 & .38 \\
3. Directions. & $(.43)$ & $(.28)$ & & .20 & .25 \\
4. Sentences. & $(.11)$ & $(.20)$ & .19 & & .36 \\
5. Arithmetic. & $(.08)$ & $(.41)$ & $(.33)$ & $(.36)$ & \\
\hline
\end{tabular}

Average $r$ between speeds - level constant $=.21$

\section{CONCIUSIONS REGARDING A SPEED ABILITY IN MATERIAL} OF VERY LOW DIFFICULTY.

It will be seen from Table XIV. that the average intercorrelation of the speed tests is practically equal to the average correlation between the speed tests and intelligence. When the influence of level of intelligence is removed, the average partial intercorrelation of the speed tests decreases very little, from .27 to $\cdot 21$. This would indicate a consistent, although small, relationship between the speeds, after level of intelligence is made constant, i.e., there is a speed ability in this material of low difficulty which is independent of what we measure as intelligence in the otis group test. The magnitude of this factor can not be estimated accurately from our data. There was not a large range of ability in the student group, (the IQs were estimated roughly from the otis scores to range from 110-140). Also, there is the question of the goodness of the otis score as a 
measure of level of intelligence.

\section{THE NATURE OF THIS SPEED ABILITY.}

Since this ability for speed in reactions of low difficulty is apparently independent of intelligence as measured, its nature is of considerable interest. From the manner in which it has been spoken of it would seem to be a pure facility in simple cognitive processes. But speed of reaction essentially involves some "drive" or energy behind it so that it cannot be dismissed with an explanation so superficial as this one, with its underlying concept of ease of nervous conduction. We have a theory of intelligence already which uses the idea of a mental energy. It may easily be that these speeds are governed by this factor, the well-known "g". This possibility is tested in the following section.

\section{$I(d)$.}

EXAMINATION OF THE DATA FOR A GROUP FACTOR OF SPEED INDE PENDENT OF "g".

We have referred to the demonstration by Professor Spearman from Bermstein's data that there is no group factor of speed, meaning, of course, no group factor apart from "g". (p. 34 ). It will be of interest to see if our own data support this conclusion. Hitherto we have been concerned with a speed factor existing independently of what is generally described as intelligence, i.e., level of intelligence. The methods of demonstrating the dependence of the speed measures upon "the common factor" are, to eliminate this factor from their interrelationships and then note whether these still persist, when "g" is constant; or (2) to examine 
the tetrad differences of the table of correlations expressing the relationships between the speeds and some measures of level. We have carried out these procedures for some of the previous data, namely, those relationships in Tables X, XII and XIV. RESULTS.

In Table X. we have the interrelations of the Performance Test speeds and the measures of level. The 15 tetrad differences are shown below with their mean and probable error. By calculating the theoretical probable error of these tetrads we are able to test whether our obtained value is significantly large or otherwise. If the obtained value falls within the limits of error allowed by the calculated value then we have proved, according to spearman, that one factor, and one factor only, is the source of the interrelations between these speed and level measures; and this one factor will be "g" since our level measures involve this to a high degree. Should the tetrads be significantly different from a distribution round zero with a probable error equal to the calculated one then we conclude that there is a factor (or factors) producing correlation in adition to that produced by " $\mathrm{g}$ ".

$$
\text { TABIE XVI. (from Table X). }
$$

With addition of correlations between each measure and "g".

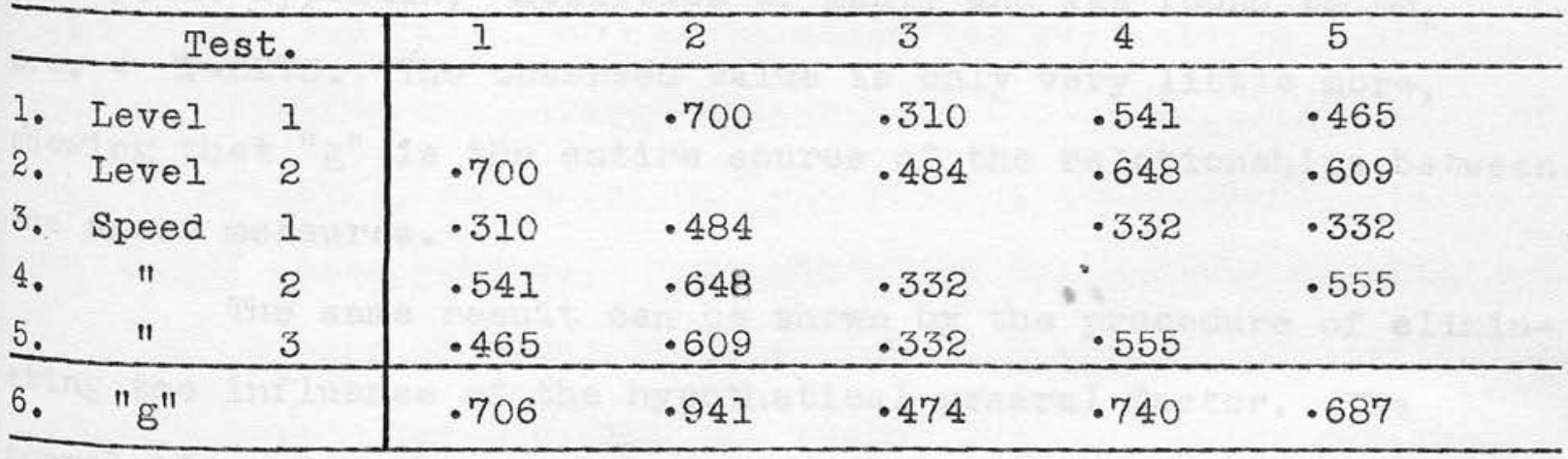


The 15 Tetrad Differences, their Mean and Probable Error.

$\begin{array}{lll}1 & .700 \times .332-.484 \times .541=(-) .030 \\ 2 & .700 \times .332-.484 \times .465= & .007 \\ 3 & .700 \times .332-.648 \times .310= & .031 \\ 4 & .700 \times .555-.648 \times .465= & .089 \\ 5 & .700 \times .332-.609 \times .310= & .043 \\ 6 & .700 \times .555-.609 \times .541= & .059 \\ 7 & .310 \times .648-.484 \times .541=(-) .061 \\ 8 & .310 \times .609-.484 \times .465=(-) .036 \\ 9 & .310 \times .555-.332 \times .465= & .018 \\ 10 & .310 \times .555-.332 \times .541= & .030 \\ 11 & .541 \times .609-.648 \times .465= & .054 \\ 12 & .541 \times .332-.332 \times .465= & .067 \\ 13 & .484 \times .555-.332 \times .648= & .013 \\ 14 & .484 \times .555-.332 \times .609=(-) .008 \\ 15 & .648 \times .332-.332 \times .609= & .026\end{array}$

Probable Error $= \pm .0299$

The theoretical probable error to be expected from these correlations was calculated from Spearman's formula for this value (16A p.xi. Appendix, "Abilities of Man") and was found to be, p.c. $= \pm .0273$. The observed value is only very little more, showing that " $g$ " is the entire source of the relationships between the speed measures.

The same result can be shown by the procedure of eliminating the influence of the hypothetical general factor. The correlation of each measurement with " $g$ " was found and this elimin- 
ated by the method of partial correlation in the usual fashion, with the results shown in Table.

TABIE XVII.

PARTIAL CORRELATIONS BETWEEN MEASURES OF TABLE $X$. WHEN INFLUENCE OF "g" IS REMOVED.

\begin{tabular}{|c|c|c|c|c|c|}
\hline & 1 & 2 & 3 & 4 & 5 \\
\hline $\begin{array}{l}\text { 1. Group Test m.8. } \\
\text { 2. Performance Score }\end{array}$ & & $\cdot 146$ & $\begin{array}{r}-.038 \\
\cdot 128\end{array}$ & $\begin{array}{r}\cdot 044 \\
-\cdot 219\end{array}$ & $\begin{array}{l}-.037 \\
-\cdot 158\end{array}$ \\
\hline $\begin{array}{l}\text { 3. Blocks Speed } \\
\text { 4. Cubes Speed } \\
\text { 5. Form Boards Speed }\end{array}$ & & & & -.032 & $\begin{array}{r}.011 \\
.096\end{array}$ \\
\hline
\end{tabular}

Average Value $=-.006$

The average value of -.006 shows that zero relationship exists between the measures when the general factor is removed. This result is not unexpected when it is remembered that the interpretation of " $g$ " as mental energy would make it involve both goodness and speed of response although it is possible as spearman says these qualities need not be equally saturated with "g".

A further way of showing the dependence of the speed measures upon "g" is to obtain the tetrad difference between two "paired" and two "unpaired" correlation coefficients, a "paired" coefficient being one between measures of the same quality $e \cdot g$. of speed or of level, an "unpaired" one being a coefficient between a level and a speed measure. From the block design test we obtained a further measure of level since it included a scale of difficulties. Using the speeds measure from the easier tests of these and the 
cubes, and the other level measure from the group test mental age the following tetrad was obtained. (Group II. 95 subjects).

$\begin{array}{llll} & \text { Blocks Score } & \text { Cube Speed } \\ \text { Age } & .534 & .482 \\ \text { Blocks Speed } & .470 & .307\end{array}$

The tetrad difference here is $.164-.227=-.063$. The calculated probable error of this is $\pm .054[(16)$ p.xi. "Abilities of Man"] so that the value is not significant.

Again, if from the student data of Table XIV. the speed measures are taken we have a' table of intercorrelations which we know to be partly dependent upon "g". If there is a group factor of speed the tetrad differences will be significantly greater than zero as before. On calculation however they show a mean value of .0595 with a probable error in their distribution of $\mathbf{\pm 0 5 0 5 . ~ T h e ~}$ theoretical value, obtained as before, is \pm .032 from which the obtained value is not significantly different.

These data are given below.

$$
\text { TABIE XVIII - (From Table XIV). }
$$

INTER- CORREIATIONS OF THE SPEED MEASURES FROM STUDENTS.

\begin{tabular}{l|ccccc}
\hline \multicolumn{1}{c|}{ Speeds. } & 1 & 2 & 3 & 4 & 5 \\
\hline 1. Directions & & $\cdot 33$ & $\cdot 28$ & $\cdot 43$ & $\cdot 19$ \\
2. Arithmetic & $\cdot 33$ & & $\cdot 41$ & $\cdot 08$ & $\cdot 36$ \\
3. Addition & $\cdot 28$ & .41 & & $\cdot 22$ & $\cdot 20$ \\
4. Cancellation & $\cdot 43$ & .08 & $\cdot 22$ & & $\cdot 11$ \\
5. Sentences & $\cdot 19$ & $\cdot 36$ & $\cdot 20$ & $\cdot 11$ & \\
\hline
\end{tabular}


Tetrad Differences from this Table.

\begin{tabular}{|c|c|c|c|c|c|c|c|c|c|}
\hline 33 & $x$ & $\cdot 22$ & - & $4:$ & $x$ & 4] & $=$ & ) & . I \\
\hline 33 & $x$ & .20 & - & .41 & $x$ & $\cdot 19$ & - & $(-)$ & - $c$ \\
\hline 33 & $x$ & $\cdot 22$ & - & $\cdot 28$ & $x$ & .08 & $=$ & & \\
\hline 33 & $x$ & $\cdot 11$ & - & .08 & $x$ & • 19 & $=$ & & $\cdot 0$ \\
\hline 33 & $x$ & $\cdot 20$ & - & $\cdot 36$ & $x$ & $\cdot 28$ & $=$ & $(-)$ & \\
\hline 33 & $x$ & $\cdot 11$ & - & $\cdot 36$ & $x$ & $\cdot 43$ & $=$ & $(-)$ & \\
\hline 88 & $x$ & • 11 & - & $\cdot 22$ & $\mathrm{x}$ & $\cdot 19$ & $=$ & $(-)$ & \\
\hline 3 & $x$ & .08 & - & .41 & $x$ & .43 & $=$ & $(-)$ & \\
\hline 88 & $x$ & $\cdot 36$ & - & .41 & $x$ & $\cdot 19$ & $=$ & & \\
\hline 88 & $x$ & .11 & - & $\cdot 20$ & $x$ & .43 & $=$ & $(-)$ & \\
\hline 43 & $x$ & $\cdot 36$ & - & .08 & $x$ & $\cdot 19$ & $=$ & & - I \\
\hline 43 & $x$ & $\cdot 20$ & - & $\cdot 22$ & $x$ & $\cdot 19$ & $=$ & & 0 \\
\hline 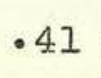 & $x$ & $\cdot 11$ & - & $\cdot 2$ & $x$ & $\cdot 36$ & $=$ & $(-)$ & \\
\hline 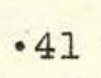 & $x$ & - 11 & - & $\cdot 20$ & $x$ & .08 & $=$ & & 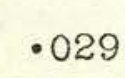 \\
\hline & $\mathrm{x}$ & .20 & - & $\cdot 2$ & $x$ & $\cdot 36$ & $=$ & $(-)$ & \\
\hline & & & & $=$ & & & & & \\
\hline
\end{tabular}

Obtained Probable Error $= \pm .0505$

Calculated " $"= \pm .032$

The theoretical frequency distribution is shown below (in red) for comparison with the observed value in this case, as the discrepancy between these values is larger than in the other cases.

\section{Observed and Theoretical (red) Distributions}

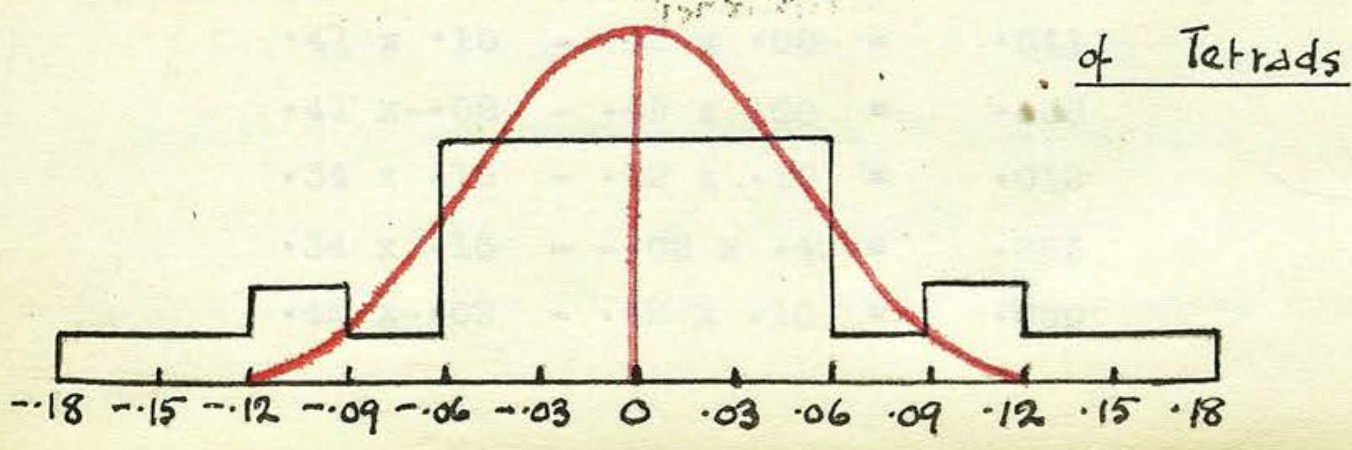


When the intercorrelations of the sub-tests in the National Intelligence Test are treated similarly we get the same result, viz., that the inteccorrelations are due to the presence of "the greneral factor".

TABLE XIX. (From Table XII).

INTERCORRELATIONS OF NATIONAL SUB-TESTS.

\begin{tabular}{|c|c|c|c|c|c|c|c|}
\hline & & & 1 & 2 & 3 & 4 & 5 \\
\hline & tional & 1 & & $\cdot 41$ & $\cdot 25$ & $\cdot 41$ & .00 \\
\hline 2. & $"$ & 2 & - 41 & & $\cdot 34$ & .42 & $\cdot 10$ \\
\hline 3. & $"$ & 3 & $\cdot 25$ & $\cdot 34$ & & $\cdot 42$ & -.02 \\
\hline 4. & " & 4 & $\cdot 41$ & $\cdot 42$ & $\cdot 42$ & & $\cdot 16$ \\
\hline 5. & $"$ & 5 & .00 & $\cdot 10^{\prime}$ & -.02 & $\cdot 16$ & \\
\hline
\end{tabular}

Tetrads from Table XIX.

$.41 \times .42-.34 \times .41=.033$

$.41 \times-.02-.34 \times .00=.008$

$.41 \times .42-.42 \times \cdot 25=.070$

$.41 \times .16-.42 \times .00=.066$

$.41 \times .02-.10 x \cdot 25=.033$

$.41 \times .16-.10 \times .41=.025$

$.25 \times \cdot 42-.34 \times \cdot 41=.037$

$.25 \times .10-.34 x .00=.025$

$.25 \times .16-.42 \times .00=.040$

$.25 \times .16-. .02 \times .41=0.048$

$.41 \times .10-.42 \times .00=.041$

$.41 \times-.02-.42 \times .00=.008$

$.34 \times .16-.42 \times \cdot 10=.012$

$.34 \times .16-. .02 \times .42=063$

$.42 x-.02-.42 x .10=.050$ 


$$
\text { Mean }=.0372
$$

Observed Probable Error $= \pm .0297$
Calculated " " $= \pm .0391$

\section{CONCIUSIONS REGARDING A GROUP FACTOR OF SPEED IN} INTELIIGENT REACTIONS.

It has been shown that a group factor of speed, i.e. a factor of speed independent of intelligence considered as the "general factor", does not exist. When speeds in tasks ranging from very low to medium difficulty for the subjects are interrelated, these interrelations have been shown to be due to "g". The evidence on this point is quite definite,

We have exemplified in these results the "general" nature of " $g$ ". It is more than intelligence as ordinarily understood. As Spearman says (41. - p.258) "g has shown itself to measure a factor both in goodness and in speed of cognitive process". The fact that speed in tasks of medium difficulty is a good measure of "g" (when the measure is made under reliable conditions) has important consequences. Thorndike's separate aspects of intelligence, especially the one of level which requires very laborious work to construct a proper scale, do not require to be measured as different abilities if the interpretation of intelligence as " $g$ " is accepted. And the concept of intelligence as mental energy is a valuable one in the explanation of the non-existence of a speed factor. As Boring (33) has said, from the fact that the times taken to do tasks is highly related to intelligence, "Intelligence ... would seem to be primarily, although as the tests test it not entirely, mental power...... The conception of intelligence as mental power, 
rould seem to give new meaning to intelligence as the 'common factor' or as 'general ability'..... Power is just such a general factor in mechanical operations. By itself it has no meaning. It is ability to do work against time, and it is exhibited only as it is utilized in some special machine or in some natural mechanism". This concept is not, of course, very different from spearman's own interpretation of " $g$ " as mental energy, but it is an interesting confirmation of Spearman's theory from a different approach.

An interesting test of this theory would be the comparison of the times taken by one individual in doing tasks of equal difficulty but doing these with varying degrees of goodness. According to the concept of power or energy, the 'output' of the individual should remain steady when maximum effort is used. This would be demonstrated if the goodness and speed could be combined into one quantity and this was shown to remain constant for the one individual. Gates (19) has used this principle in the case of handwriting. When the quality of the writing was rated, it was found that over a fair range of quality, the quantity - quality. rating $\times 3 \sqrt{\text { speed, }}$ remained constant for one individual. This would be a much more difficult problem to deal with in the case of intelligence but it seems highly possible that a similar constancy for each individual could be shown. 


\section{ANALYTTCAL DATA ON THE SPEED FACTOR.}

(a) The Nature of the Time Differences in Solving the Performance Test Problems.

The evidence in this part of our investigation consists of the relationships found between the times taken to the performance test problems and the number of steps in these, as recorded by the observers.

\section{METHOD and RESULTS.}

The data were obtained from the subjects of Groups I and II, 36 boys in the former, but from the other group of nearly 200 youths records were kept for only 95 of them as it was thought advisable not to have too many observers when the data were of a slightly subjective character. The subjective influence enters, of course, in the recording of a "rnove" or a "step". In his account of the Block-Design Test Kohs recorded the number of moves made, his definition of a move being as follows (28, p.76): "A move is counted when a block is given its initial position on the table. Each separate and distinct change in the position of a block is counted a move. Sometimes a child will make three or four changes in the position of a cube, the topside remaining the same color (especially true of diagonal sides, e.g. red-white). But each change in position is counted a separate move". Because such changes are often made to all appearances in an aimless fashion, for instance, when the subject is not looking at the block but is considering the design and moves the block almost mechanically, from perseveration, we have used a slightly modified definition. 
A move was counted as any change of position of a block or blocks (sometimes two blocks were moved together and this was counted as one move) when this was apparently considered in relation to the whole.

With Group I, there were two observers but the recording was practiced beforehand to ensure both recording similarly. With Group II, three observers kept records and the median numbers of moves for the group tested by each one were compared, to discover any wide variations in the records. These groups numbered about 30 in each but that of Tester I was significantly brighter than the other two, while that of 2 included more defectives than the others. The median numbers compare sufficiently well however to include all the data in one group for further treatment. The actual medians are presented in Table $\mathrm{xx}$.

\section{TABLE XX.}

NEDIAN NUMBER OF MOVES IN DIFFERENT TESTS FOR THREE GROUPS TESTED BY DIFFERENT OBSERVERS.

\begin{tabular}{cc|c|c|c|c|c|c|c|c|c}
\hline Tester & 1 & 6 & 7 & 7 & 7 & 13 & 11 & 22 & 22 & 25 \\
$" 1$ & 2 & 7 & 10 & 8 & 9 & 19 & 15 & 28 & 20 & 24 \\
11 & 3 & 5 & 7 & 4 & 9 & 21 & 10 & 31 & 22 & 27 \\
\hline
\end{tabular}

The correlations between the number of moves and time taken for the two groups are presented in Table XXI.

\section{TABLE XXI.}

CORRELATIONS BETWEEN TIME AND MOVES IN PERFORMANCE TESTS. 


\section{BLOCK - DESIGNS.}

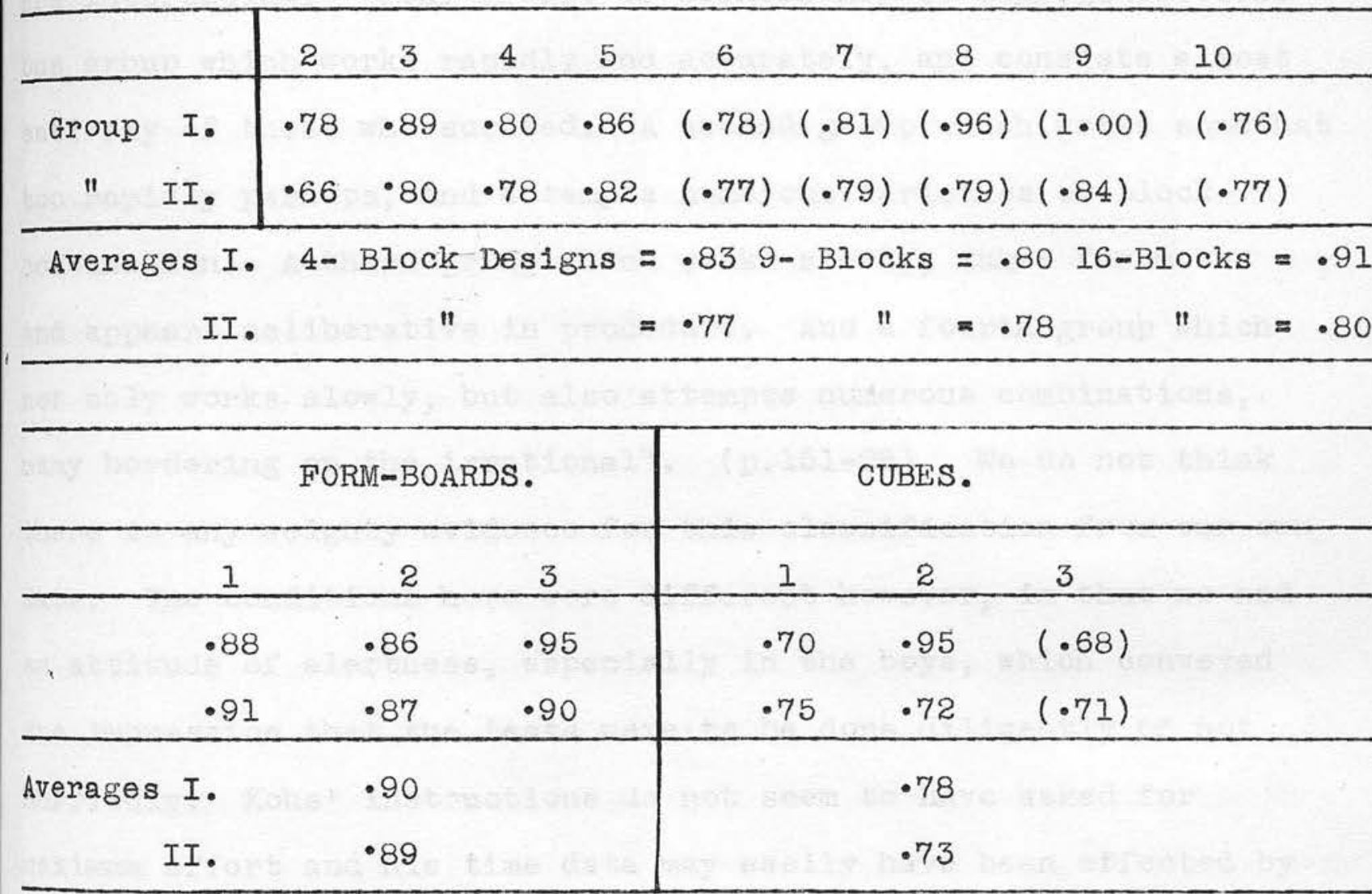

Grand Average Group I. $=.83$ Group II. .81

\section{CONCLUSIONS FROM ANALYTICAL DATA.}

The relationships between steps taken and time are therefore seen to be almost perfect allowing for the errors of measurement. Kohs also found these to be high although his figures are not quite so high as ours. For the 4- block designs, his correlation between time and moves was $r=.76$ (590 subjects) which is in agreement With our value from Group II. of .77; for the 9- block designs his figure falls to .58 ( 103 subjects) compared with our value of .78 , While his figure for the 16- block designs $\cdot 70$ (146 subjects) is a little lower than our value, 880 . His 9 - block figure seems to be 
exceptional. The conclusions he reached from these relationships are interesting. "Four groups of workers may be segregated..... one group which works rapidly and accurately, and consists almost entirely of those who succeed. A second group which works somewhat too rapidly perhaps, and attempts numerous varieties of blockcombination. A third group which works slowly, makes few moves and appears deliberative in procedure. And a fourth group which not only works slowly, but also attempts numerous combinations, many bordering on the irrational". (p.151 28). We do not think there is any weighty evidence for this classification from our own data. The conditions here were different however, in that we had an attitude of alertness, especially in the boys, which conveyed the impression that the tests were to be done diligently if not hurriedly. Kohs' instructions do not seem to have asked for maximum effort and his time data may easily have been affected by this variable. It is also possible that our slightly different definition of a move accounts for our higher relationships. From our data we think there is cogent evidence that there is a general tendency to make steps towards the solution of the problem at not very different rates. The poorer intelligences take more time in solving a problem simply because they require to make more steps. And probably this is also true to a great extent in the items of the usual intelligence tests. This is not meant to imply that the poorer individuals make more trial-and-error until the lucky chance comes. Repeatedly a subject of this type will hold an element quite close to the design in the Blocks Test, for example, turned the proper way, yet he will fail to put it into the 
whole. It seems that he requires to repeat and make more steps until he sees the relevance of a particular one. Certainly the existence of a slow deliberate type making few moves very cautiously is a rare exception, however much everyday observation seems to be opposed to this finding. It is to be remembered, of course, that speed in everyday intelligent actions is a different matter. Under test conditions we try to preserve a uniform "drive" which is seldom present in the ever changing situations of the individual's usual actions. Moreover a person normally described as deliberate seldom is so because his intellectual processes occur slowly. Rather, we think, is it the very opposite. The deliberate person is he whose processes are occurring so differently from the others that his response is of a different type entirely. The so-called impulsive type responds quickly because he does not see so far as the deliberate one who is restrained by aspects of the situation never apprehended by the other.

\section{$2(\mathrm{~b})$.}

TEMPERAMENTAL TRAITS AND THE SPEEDS IN INTELLIGENT REACTIONS.

Since the hypothetical group factor of speed would appear to involve certain temperamental qualities to a high degree, measures of these should exhibit positive relationship with the speed measures. Temperamental traits are not easily assessed however. The chief instrument for this purpose, the June Downey Will-Temperament Test, has been subjected to considerable criticism both from a practical and from a theoretical standpoint. The reliability and the norms have been questioned and some doubt has been cast upon the validity of the methods and their interpretations. Accepting it as a rough 
scale however, we gave it in the group form to the 86 students of Group III.

RESULTS.

Measures: The group form of the Downey Test was given according to the published instructions. It comprises twelve tests.

From the traits tested, certain ones which might be expected to have some influence upon the times taken in intelligent reactions were selected, and their inter relationships with the speed measures determined. These were the four tests measuring "speed and fluidity of reaction", Tests 1, 2, 3 and 4 of the series. Test I, "Speed of Movement", gives a measure "eminently characteristic of the explosive temperament..... The rapidity with which different individuals walk, gesture, or talk, ......." Test 2, "Freedom from Load", .... "suggests that the psychic machinery mus with little friction;... its own inherent energy holds it at top speed".

Test 3, "Flexibility". Because of its correlations with the other speed measures and its measure of the degree to which individuals are habituated in their reactions, this trait would be expected to reveal any tendency to perform a variety of reactions in a particular fashion.

Test 4, "Speed of Decision". "The purpose of the test is to determine the speed of the subject in reaching decisions" evidently a very probable constituent of a speed factor.

(2) Two tests, 6 and 8 of the series, which might serve as indicators of a possible speed difference due to differences in self-criticism or allied qualities. Having solved a problem, different subjects 
may exhibit consistent differences in their confidence in the result and hence in the times taken to say they had finished. Test 6, "Reaction to Contradiction" and Test 8 "Finality of Judgment" assess individuals with regard to the degrees of "forcefulness" and "a tendency to return again and again to a reconsideration of the judgments they had passed".

(3) Tests 10, 11, and 12 of the series as measures of carefulness. Test 10, "Interest in Detail", explains itself as a trait which might cause a factor of slowness.

Test 11, "Co-ordination of Impulses", to test "the ability to act both quickly and correctly".

Test 12, "Volitional Perseveration". "It measures a native tendency to 'keep on working', psychic momentum".

The quotations are taken from Downey's description of the tests (13).

The speed measures were those used before along with three others, namely, (I) a series of harder sentence completions from which only those sentences done correctly by all were taken. Each separate sentence was timed so that the ones selected could be combined to give a composite measure of the speed at which they were performed on the whole. The instructions for these were 'to do them as quickly and as well as possible'.

(2) A similar series giving a similar measure but this time with instructions to do them as carefully as possible, choosing the best words rather than the first one thought of, to fill up the blanks.

(3) The time taken to read paragraphs and answer 
correctly a few questions on them. (These were taken from the Van Wagenen Scales). Four paragraphs were given but only two were done correctly.

Table XXII. shows the correlations between the various speed measures and the temperament tests and also between both of these series and intelligence (otis Score). None of the relationships between temperament and speed are significant.

\section{TABLE XXII.}

CORRELATIONS BETWEEN TEMPERAMENTAL TESTS, SPEED MEASURES AND INTELIIGENCE. (LOWEST STATISTICALIY SIGNIFICANT $r=\bullet 35$ ).

\begin{tabular}{|c|c|c|c|c|c|c|c|c|c|c|}
\hline Speed Tests. & $\begin{array}{r}\text { In } \\
\text { tell }\end{array}$ & 1 & 2 & $3^{T \epsilon}$ & $\begin{array}{l}\text { empere } \\
\end{array}$ & $\begin{array}{c}\text { ament } \\
6\end{array}$ & $\begin{array}{c}\text { Test } \\
8 \\
\end{array}$ & 10 & 11 & 12 \\
\hline 1.Cancellation Speed & .41 & $\cdot 27$ & $\cdot 22$ & $\cdot 10$ & .15 & $\cdot 23$ & $\cdot 12$ & $\cdot 13$ & • 19 & $-\cdot 13$ \\
\hline 2.Addition " & $\cdot 20$ & -.067 & -098 & $\cdot 12$ & .091 & .19 & $-\cdot 065$ & $\cdot 24$ & -.033 & .099 \\
\hline 3.Directions " & .44 & $\cdot 26$ & $\cdot 10$ & .079 & .095 & .049 & .052 & $\cdot 12$ & $\cdot 136$ & $\cdot 032$ \\
\hline 4.Arithmetic " & $\cdot 24$ & .064 & $-\cdot 082$ & $\cdot 012$ & .24 & .17 & $\cdot 044$ & .014 & -0084 & $4-.18$ \\
\hline $\begin{array}{l}\text { 5. Reading and } \\
\text { Comprehension }\end{array}$ & $\cdot 21$ & $\cdot 13$ & -.019 & - 011 & .044 & .067 & - 099 & .000 & $\cdot 124$ & $-\cdot 15$ \\
\hline 6.Sentences Quick & $\cdot 39$ & .080 & .013 & $\cdot 33$ & .045 & .14 & .009 & .091 & $1 \cdot 007$ & -.067 \\
\hline Careful & .27 & $\cdot 23$ & $\cdot 22$ & -.002 & .17 & $\cdot 16$ & .044 & $-\cdot 16$ & $\cdot 15$ & .027 \\
\hline 8.Intelligence & - & $\cdot 054$ & $\cdot 17$ & $\cdot 19$ & $-\infty 18$ & .06 & $\cdot 21$ & $\cdot 14$ & $\cdot 04$ & -.08 \\
\hline $\begin{array}{l}\text { 9. Composite of } \\
\text { Speed Tests } \\
\end{array}$ & $\cdot 37$ & .14 & .031 & .13 & .15 & .14 & .071 & .11 & .074 & -.081 \\
\hline $\begin{array}{l}\text { Average } r \text { between } \\
\text { Speed Tests and } \\
\text { Temp. Tests. } \\
\text { (Speeds } 1-6 \text { above) }\end{array}$ & . 315 & - 123 & .023 & $\cdot 109$ & .111 & •139 & .044 & .093 & .058 & -.065 \\
\hline
\end{tabular}

Statistically but it is evident that, from the number of the coefficients which are positive, low relationships exist in most 
cases. The negative relationships between the speeds and Test 12 would, of course, be expected since a high score in this test indicates a large amount of perservation. The low negative relation confirms the results of Bernstein and of Lankes (4), "that the perseverator on the whole tends to be slower than the non-perseverator"; but the result is so low as to be negligible in practice. Downey's measure is not quite of the same nature as those investigators used, being a perseveration of will, but the two measures have much in common.

The average correlations between the various speed measures and the temperamental qualities are included in the table, as also are the correlations between a composite of the first six speed tests in the table and the temperamental qualities. These values are all very low. It would seem therefore that temperamental traits, if we accept the measurement of these by the June Downey Test, do not influence the speeds in intelligent reactions of medium or very low difficulty.

\section{CONCLUSIONS FROM THE TEMPERAMENT TEST MEASURES.}

Temperamental traits as measured by the June Downey Test correlate only very lowly with speed measures, no matter whether these speeds are in material of very low or moderately high degree of difficulty. Since the intelligencemeasure also correlates very lowly with the temperamental traits it cannot be said that these low relationships are significant for the existence of a speed factor of temperamental origin. As said before, temperamental differences in the choice of speed of work in everyday life are bound to be more or less eliminated in a test situation. The absenee 
of a speed factor as shown from these data confirms the previous findings, that speed in processes, when these are executed with maximum effort, is dependent chiefly upon factors intimately related to intelligence. 


\section{CHAPTER V.}

SUMMARY and CONCLUSIONS.

1. The Measurement of intelligence by the use of time-limit tests has revived an old problem in the question of quickness and (or versus) ability. These tests have been reproached with the statement that they involve too much speed and not intelligence, - and obviously this criticism implies much that is of importance to the psychologist. Three problems have been separated for convenience; actually, they are aspects of the same problem. These are as follow:

1. Does a time-limit invalidate a test as a measure of intelligence?

2. Is there a factor of quickness in intelligent reactions?

3. What is the nature of the time differences in intelligent reactions?

2. Taking these questions in order we find that -

(1) Previous work has shown that a time limit does not invalidate an intelligence test. When the time limit is removed the scores made in these long times correlate very highly with the scores made in the restricted times.

(2) A speed ability independent of intelligence has been shown to exist. This speed however does not seem to us to be the one implied in the criticism against the intelligence tests for it is a speed in material of almost zero difficulty. The speed ability which is implied when the time-limit tests are criticised is a speed in intelligent reactions of fair difficulty - a speed of thought or of intelligent process. 
Few investigators have sought to isolate a speed of this nature. The chief investigation by Bernstein found no speed factor in intelligent reactions, but his procedure does not appear to be quite valid.

(3) Boring assumed the times taken in intelligence tests to be entirely dependent upon intelligence, and he sought to analyse the time differences by finding the relation between times in simple processes and the times in intelligence test items. The simple processes such as association time, reaction time etc., were thought to be constituents of the intelligent act. A large amount of work, however, has shown that speed in these simple processes is unrelated to the speed in intelligent reactions.

3. We have suggested that a crucial test of the existence of a factor of quickness in intelligent reactions, would be to intercorrelate the actual times taken to tasks of moderate difficulty, and then to obtain the partial intercorrelations of these times when the factor of level was made constant. This was done with a large group of subjects, when it was found that almost the whole of the correlation between the times taken to do simple problems was due to the factor of level of intelligence (i.e. intelligence as ordinarily understood). Thus, there seems to be little evidence for the view that some individuals can think quickly without being able to think well.

4. If, instead of intelligence as ordinarily understood, we interpret this as "the general factor", there is no group 
factor of speed in intelligent reactions. "g" has been shown to be the entire source of the intercorrelation of speed and

level measures. This finding supports the interpretation of intelligence as mental energy or power - the ability to do intellectual work against time.

5. By using performance tests, a method of observing the intelligent process in a problem was made possible. Here it was found that the times taken to problems were very highly correlated with the number of steps. This supports the finding of no speed ability in intelligent reactions because it shows that the time taken to the problem is chiefly determined by the number of steps required and the ability to solve a task in a few steps is evidently closely associated with intelligence. There is practically no tendency for subjects to exhibit 'slow-deliberate' steps or 'quick, rash' ones. It is to be remembered, of course, that here we are dealing with reactions under test conditions. In normal life, wide speed differences might be evinced from a great number of accidental factors.

6. Temperamental traits as measured by the June Downey Scale showed little relationship to the speeds in intelligent reactions. Here again, we should expect this from the special conditions of the test measures, which tend to eliminate differences of a temperamental character.

7. From our results taken together, we cannot but conclude that the time taken to solve problems is dependent upon intelligence, when the individual is exerting maximum effort. I'he time in few problems is, of course, far too susceptible to accidental 
influences to be used as a reliable measure of intelligence, but when a long series of problems is used, the rate of intelligent reaction is highly correlated with intelligence in the sense of level of intelligence, and perfectly correlated with intelligence as " $g$ ". This result proves the validity of the time-limit measure of intelligence from tests which would not actually exhaust the abilities of the subject under no time-limit conditions. 


\section{A P P E N D I X. \\ THE REFLEX LATENCY AND WENTAL ABIIITIES.}

The publication of reports in which it was stated that a high relationship existed between reflex latency and certain mental abilities was of exceptional interest. Extensive confirmation was desirable before interpretation was attempted. Since the latency was being considered as a measure of the speed of nervous conduction in these relationships, the ideal method of measurement was the one which recorded the latency of the neural paths as directly as possible. That is, it was the method which measured the period between the stimulus and the arrival of the nervous impulse at the efferent end of the arc without waiting for this to be manifested in the particular mascular movements. By means of a beautiful technique employing amplification of the action current, Travis used such a method, obtaining on one film the three parallel records of time, and the moments of stimulation and arrival of this electrical change in the executant muscle. Rounds, however, used the much less expensive method of measuring the latency by recording the muscular movements so we decided to try this.

\section{METHODS.}

Literature on the recording of the Patellar Reflex is copious. The best technique using the movements of the muscles is that evolved by Dodge (12) who devised a sensitive method of recording the contraction of the quadriceps muscle myographically. The type of record obtained is illustrated in Fig.I, line A. 
Figure 1 .

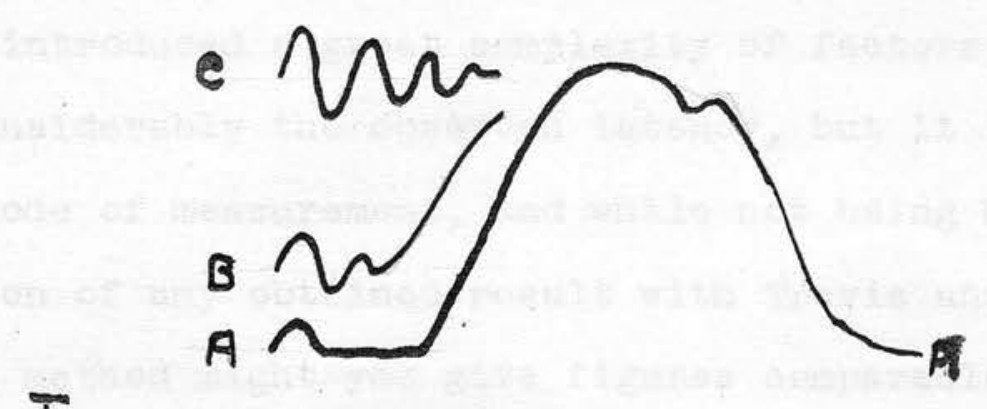

Tims monnm

Reading from the left, the first bump in the line indicates the movement of the whole muscle due to the stimulus blow on the patellar tendon, while the reflex contraction is indicated by the large rise which follows shortly after. Unless very careful precautions are taken, however, and in many cases despite these, because of the nature of the particular muscle, records are often of the form shown by line B. In such cases it is almost impossible to say. where the reflex begins, the curve representing the superposition of two separate forces. There is the initial wave which left alone would give a curve corresponding to the purely mechanical vibration of the muscle body, that is, a curve of the usual damped oscillation type as represented by line $C$. Then there is the arrival of the reflex contraction which may coincide with any phase of the muscular vibration, and although the new movement completely supersedes the previous one, the period of interaction between the forces will be a variable one and large errors enter into any estimates of the latency from such records. Rounds experienced this difficulty in his records of the Achilles reflex when recording the contraction of the Gastrocnemius muscle. On trying this method with boy subjects it was found almost impossible to eliminate this trouble, so we decided to 
try the very crude method of recording the actual movement of the limb. This introduced a great complexity of factors and naturally increased considerably the observed latency, but it is a very convenient mode of measurement, and while not being hopeful regarding the comparison of any obtained result with Travis and Hunter's results, the method might yet give figures comparable with those of Rounds.

The essentials of the method are simple. The moment of stimulation and of the first movement of the limb are recorded on the smoked drum along with a time record from a tuning fork giving say $100 \mathrm{~d} \cdot \mathrm{v}$. per second. Details of the 'setaup' are given at the end, where photographs of this and of a typical record are shown. Difficulty in deciding the point of initiation of the movement was encountered with some records, namely, those in which the recording lever did not rise abruptly, an example of this being also shown on the photograph. This introduced the possibility of errors in the measurement as large as $10 \%$, the difficulty being accentuated by the fact that most of the individuals giving records of this type gave all their records similarly. The error was minimised by having one observer select the limits of the latency on all records. It may be noted that Rounds results and even those of Travis are not free from an error of this sort and of the same magnitude. 50 records were made at the one sitting of each subject. These all gave a central value around which there was a normal scatter in most cases, typical examples being shown at the end, where it will be seen that there was a fairly large variability in most cases. As a test of reliability the alternate values were made 
into distributions for each individual and the means of these correlated .93 showing a highly satisfactory correspondence. That our measures were of a very crude order was shown by their magnitude, the mean latency being approximately $100 \sigma$, against $25 \sigma$ by Travis and Hunter, and $53 \sigma$ by Rounds. There was no doubt, however, about their reflex character. From observation they were quite uncontrolled. Also, a voluntary kick as measured showed a latency two to four times as long as the reflex, a result confirmed by data from Schlosberg (40) who found this reaction time to be about $400 \sigma$. However, if not comparable with Travis and Hunter's data they are comparable with those of Rounds. The mental measures we obtained for studying the relationship with reflex latency consisted of (a) a measure of intelligence, the Herring mental age (b) measures of speeds in various simple processes, with which the reflexes might be expected to have fair relationship. These were,

(i) Simple Reaction Time. This was measured as the simple muscular reaction of reacting to the illumination of a small lamp. This was not a very good stimulus to use if absolute values had been required but it was chosen because of convenience and the entire elimination of noise in the giving of the stimulus. 60 reactions were obtained from each subject and the median of the last 50 was taken as the measurement for comparison. Two subjects were always taken together so that rest periods could be given without expense of time.

(ii) Cognitive Reaction Time was measured by the times taken to recognize words, these being spoken into the sound key immediately after they were recognised. 10 practice words 
were given and then 20 four-letter and 20 six-letter words in series of 10. The times of response to the two lengths of words were similar so the median value of those 40 times was used.

The Hipps Chronoscope was used in both these measures. (iii) McDougall's Dotting Machine was used to obtain a further speed measure. Though designed as a test of concentration of attention the measure is undoubtedly a speed measure since we record a series of "discrimination reactions performed at full, or nearly full speed" (Burt). The subjects were given trials at increasing speeds. For each S, a graph of the number of dots correctly marked, against the number of dots per period of 15 seconds, the length of the trials, was plotted. From this the highest values corresponaing to $80 \%$ and $90 \%$ accuracy were taken. The latter was taken as the value for comparison with the other measures. The two sets of readings intercorrelated highly, $\boldsymbol{P}=.89$, a satisfactory reliability.

(iv) Speeds in Addition and Cancellation were obtained in the usual fashion, the addition being of single digits in groups of three, and the cancellation of certain letters from jumbled type.

The rellabilities of the speed measures were all high. Alternate observations of the two reaction times correlated $p=.88$ and $\boldsymbol{\rho}=079$ for the simple and cognitive reactions respectively, while the two halves of the addition and cancellation measures correlated .85 and $\cdot 91$ respectively. The subjects were the 36 boys of 
Group I. in the main inquiry.

Results - The inter-correlations of the measures are presented in Table

\section{TABIE XX.}

INTER-CORRELATIONS OF REFLEX SPEED, INTELIIGENCE AND VARIOUS SPEED MEASURES.

\begin{tabular}{|c|c|c|c|c|c|c|c|c|c|}
\hline & 1 & 2 & 3 & 4 & 5 & 6 & 7 & 8 & 9 \\
\hline 1. Herring M.A. & & $\cdot 47$ & $\cdot 27$ & $\cdot 23$ & $\cdot 23$ & $\cdot 19$ & -.44 & -.07 & .15 \\
\hline 2. Performance & & & $\cdot 31$ & $\cdot 63$ & $\cdot 35$ & $\cdot 37$ & $\cdot 56$ & $-\cdot 22$ & $\cdot 27$ \\
\hline 3. Addition & & & & $\cdot 45$ & $\cdot 04$ & $\cdot 19$ & $\cdot 14$ & $\cdot 24$ & -.10 \\
\hline 4. Cancellation & & 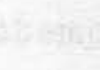 & & & $\cdot 34$ & $\cdot 47$ & $\cdot 27$ & .05 & $-\cdot 13$ \\
\hline 5. Reaction & & & zi: & & & $\cdot 42$ & $\cdot 35$ & -19 & $\cdot 18$ \\
\hline 6. Cognition & & & & & & & $-\cdot 19$ & -.36 & $\cdot 33$ \\
\hline 7. Dotting & & & & & & & & $-\cdot 15$ & .09 \\
\hline 8. Reflex & & & & & & & & & $-\cdot 47$ \\
\hline 9. Chron. Age & & & & & & & & & \\
\hline
\end{tabular}

Average Correlation of Reflex Speed and Speeds 3 to $7=-.082$ " " " " "Intelligence = -. 14 These results, although complicated by the age factor, show no relationship between the reflex speeds and the other measures excepting chronological age. The high negative relationship between these two we thought to be due to the influence of physical factors; the differences in weight of the legs were bound to affect the measure considerably. The method, of measuring the latency was therefore altered to give data upon which some reliance could be placed, the method used by Rounds being adopted, namely, to measure the Achilles reflex latency by recording the contraction 
of the gastrocnemius muscle. A group of 18 youths who had been attending the laboratory for another purpose served as subjects. The mean value of the latencies from these subjects, $58 \sigma$, agreed well with Rounds figures of $53 \sigma$ but we were sceptical of the reliability of this measure. At different sittings mean values differing by as much as 6 to $8 \sigma$ were obtained although conditions at each sitting were noted and reproduced as clearly as possible. The correlation between the latencies and intelligence (group test scores) was negligibly small.

Being of the opinion that myographic methods were too unreliable we made an attempt to measure the action currents as in Travis and Hunter's method by means of a capillary electrometer. After some work a capillary was obtained which responded to the action current of voluntary contraction of the gastrocnemius muscle but it was apparent that experimental difficulties were to be great. Further work, however, was stopped with the publication of the negative finding under rigorous conditions.

The first techniques used are given because of the possible use in connection with other reflex problems, e.g., the conditioning of the patellar reflex.

\section{EXPERIMENTAL TECHNIQUE FOR THE REFLEXES.}

The requirements of the technique were,

(I) a constant source of stimulation,

(2) a record of the moment of stimulation,"

(3) a record of the reflex response,

(4) a time record. 
1. The usual method of obtaining this is by use of a pendulum hammer such as is described by Dodge (12A). We were indebted to Prof. Sir E.S.Sharpey-Schafer however for drawing our attention to a very compact and convenient electrical stimulating device described by C.A.Johnson (25). (It was found that $1 \frac{1}{2}$ Ibs. of 22 S.W.G. wire had to be added to get a good "kick" when using the hammer off the lighting circuit in series with a resistance of $50 \mathrm{ohms})$. By altering the resistance the strength of the stimulus could be controlied.

2. When the contraction of the muscle is used, the stimulus is recorded by the vibration of the muscle. In recording the movement of the leg, the moment of stimulation was recorded by a marker magnet actuated simultaneously, by means of a twopole switch, with the closing of the hammer circuit. The lag between the blow of the hammer and the moverent of the magnet was determined by having the hammer strike the rigid leg lever (described below), which moves simultaneously with this blow; it was found to remain constant.

3. The movement of the leg was recorded by fixing a rigid lever to the ankle of the form originally devised by Keith Lucas. A modification to make the lever adjustable to different lengths of leg was introduced.

4. Recording was done on a kymograph moving vertically as well as rotating, thus giving a spiral record. Since the speed of the drum was not uniform the time was recorded continuously by a tuning fork marking the drum directly.

The arrangement of the apparatus and a typical record may 
be seen in the accompanying photographs. The subject was seated comfortably on a table, so that the edge fitted well into the back of the knee, and then given some light reading material. The experimenter operated the hammer from the switch on the table; during the recording he was screened from the subject. The leg lever, magnet, and tuning fork were placed against the drum and their relative vertical placings noted by moving the drum up and down. Stimulations were given every six seconds. With many subjects there was a marked tendency to anticipate or condition the reflex so the period was varied slightly in an irregular fashion. A few subjects inhibited the movement, but by diverting their attention, telling them to clasp hands tightly, this was generally overcome. No wamings were given and the interval of six seconds was found long enough for the muscles to relax to normal.

With the Achilles reflex we used a modification of Rounds' method. He arranged for the subjects to be seated, and by a series of fixtures the limb was kept rigid except for the deflection of the foot from the ankle joint. We adopted what seemed a simpler yet satisfactory method. The subject stood at the side of a strong table and then placed one leg on a support so placed that it was only necessary to bend this leg back from the knee, into a kneeling position, to have it on the support. The gastrocnemius was thus in a convenient horizontal position for attaching the muscle lever. The lower leg was fixed in this horizontal position with the foot hanging free at the end. In this case, of course, the recording was simplified as the lever marked the stimulus and response. Timewas recorded as before and the hammer used before served here also. 
SOME TYPICAL OISTRIBUTIONS OF THE LATENCIES OBTAINED FROM INDIVIOUAL BOYS.

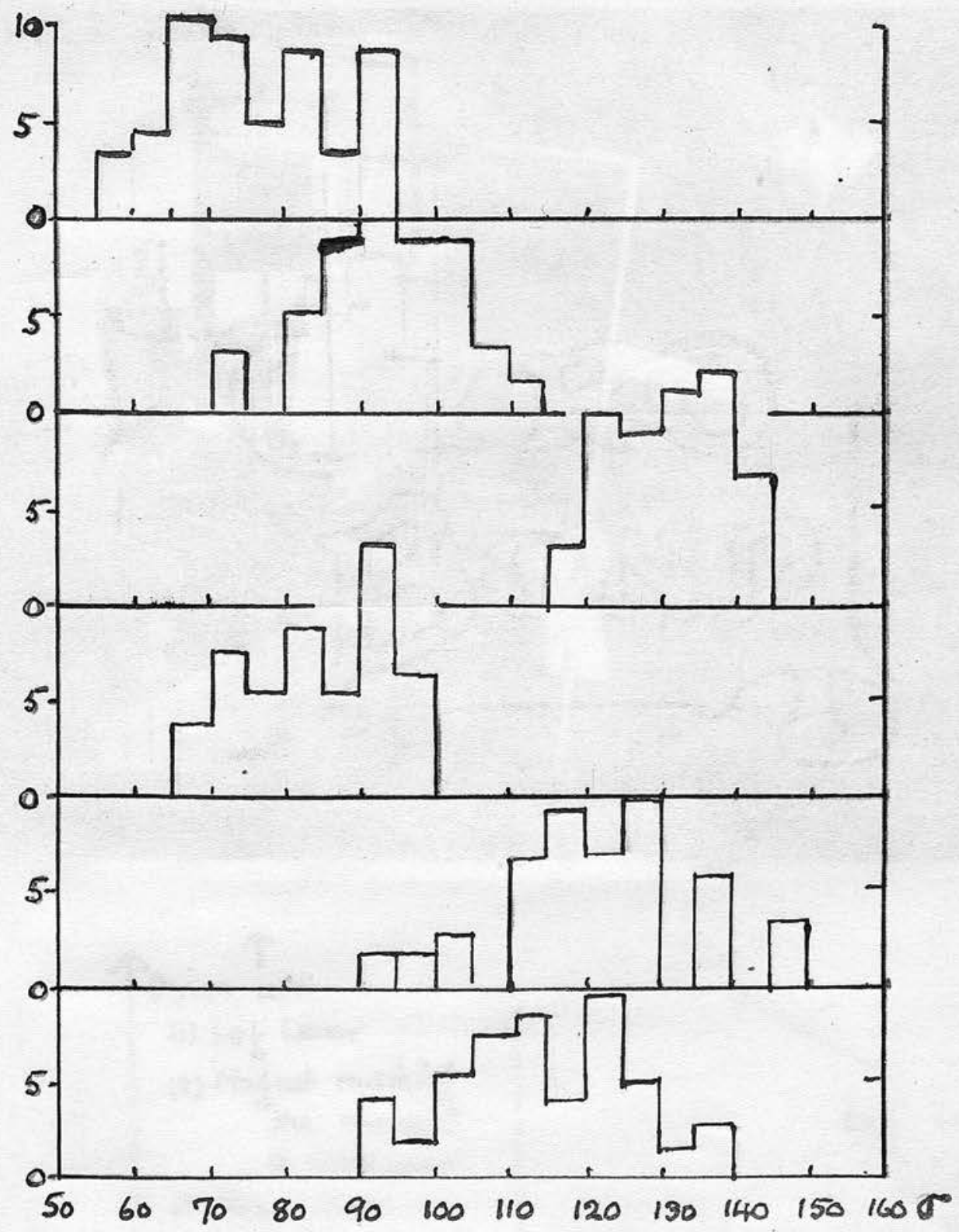




\section{'SET-UP' OF APPARATUS FOR RECORPING}

MOVEMENT OF HEG IN KNEE JERK

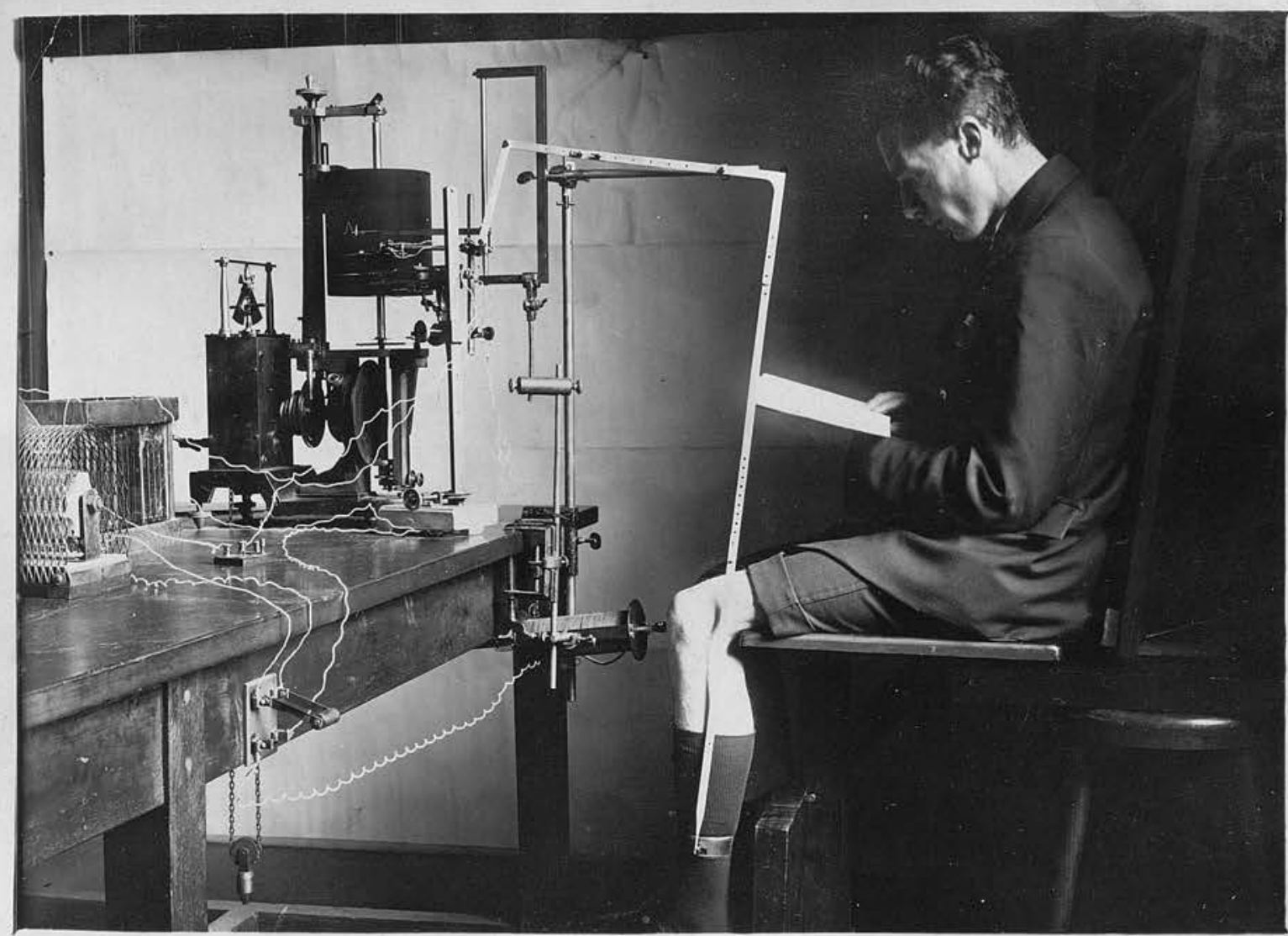

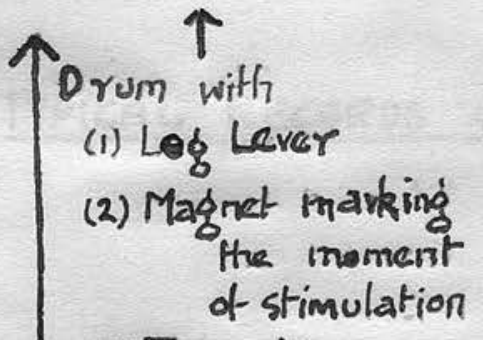

(3) Time line.

2-Pole switch

operating hammer and madinet (2).

$$
\uparrow
$$

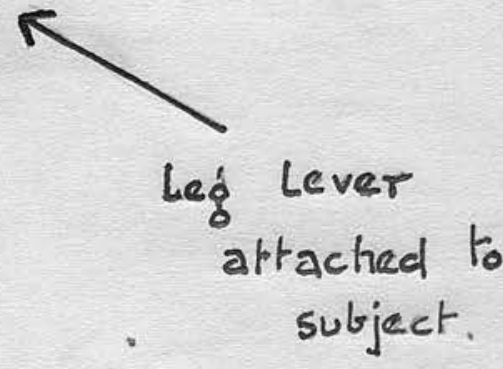

Hammer

with head

on parcllar rendon. 


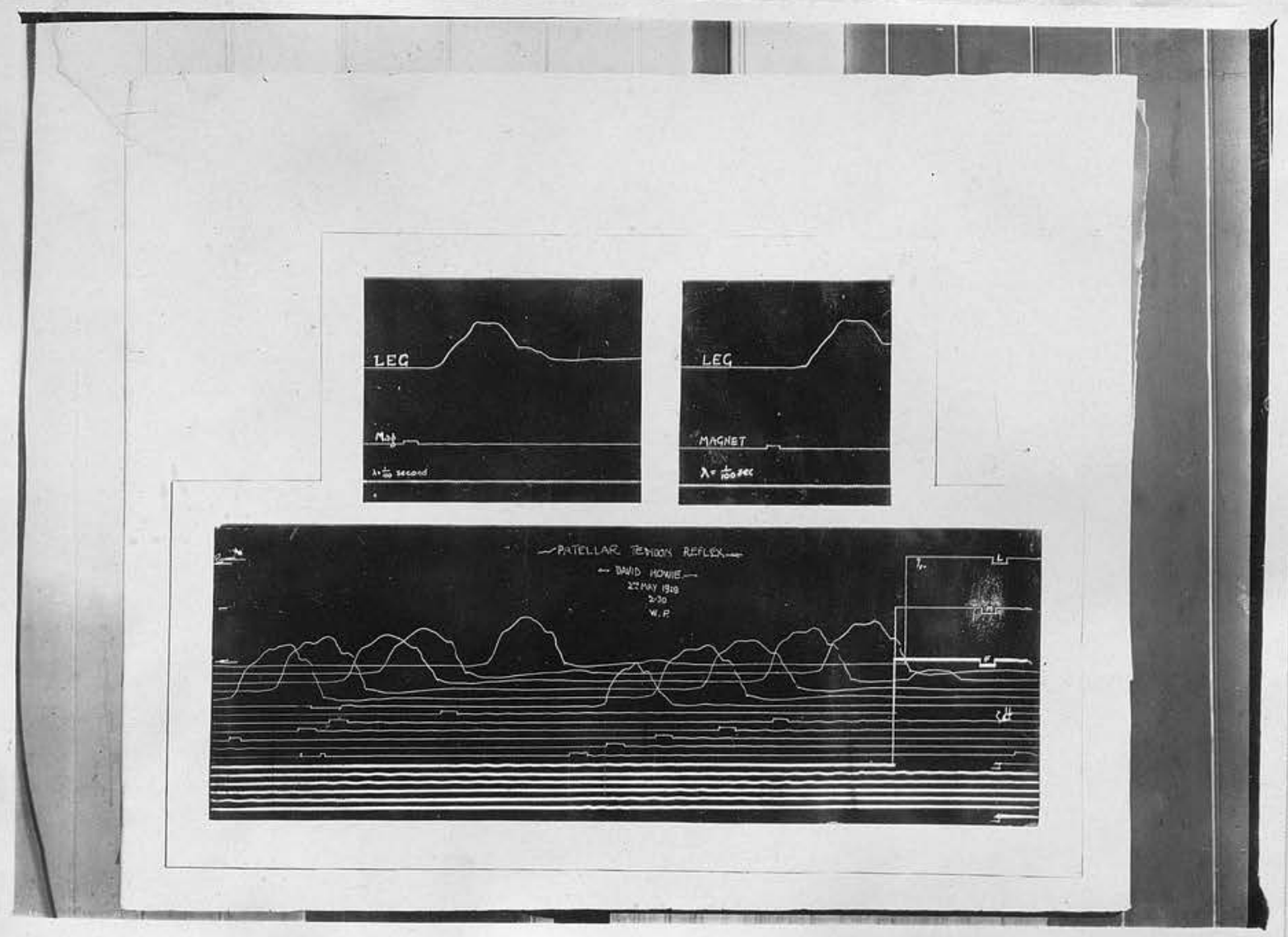

TYPICAL RECOROS OF KNEE JERIS 


\section{BIBLIOGRAPHY。}

1. Anderson, M. "An Investigation into the Rate of Mental Association". J.Educ.Psychol. 1917, Vol.8.p.97.

2. Aikins, Thorndike and Hubbell. "Correlation Among Perceptive and Associative Processes": Psychol.Rev. 1902, Vol.9, p. 374 .

3. Bagley, W.C. "On the Correlation of Mental and Motor Ability in School Children". Am.J.of Psychol. 1901, Vol.XIl. p.193.

4. Bernstein, E. "Quickness and Intelligence". Brit.J.Psychol. Monog. 1924.

5. Binet, A. "Le Psychologie individuelle". I'année psychol., 1896, Vol.2, 119.

6. Binet, A. "Attention et Adoption". L'année psychol., 1900, Vol.6, p.248.

7. Brown, Wm. "Some Experimental Results in the Correlation of Mental Activities". Brit.J.Psychol. 1910, Vol.3, p.296.

8. Brown and Thomson. "Essentials of Mental Measurement". Cambridge Psychological Library, 1921.

9. Burt, C. "Experimental Tests of General Intelligence". Brit.J.Psychol. 1909, Vol.3, p.94.

10. Burt, C. with Moore, R.C. "The Mental Differences between the Sexes". J.Exper.Ped. 1912. Vol.1, p.273 and 355.

11. Clark, J.R. - The Reference 43 - p.405.

12. Dodge, R. "Systematic Study of Knee Jerk". Zeit. t. allg. Physiologie, Vol.12, p.l.

12-A. Dodge, R. "Neuro-muscular Effects of Moderate Doses of Alcohol". Proc.Nat.Acad.Sci., 1915, No.50.

13. Downey, J.E. "The Will-Temperament and Its Testing". World Book Company, 1923.

14. Drever and Collins. "Performance Tests of Intelligence". Oliver and Boys. 1928.

15. Farmer, E. "A Group Factor in Sensory-Motor Tests". Brit.J.Psychol. 1927, Vol.17, p.327.

16. Farnsworth, Seashore and Tinker. "Speed in Simple and Serial 
Action as Related to Performance in Certain Intelligence Tests". Ped.Sem.1927.

17. Freeman, F.S. "Power and Speed - Their Influence upon Intelligence Test Scores". J.of App.Psych. Vol.12 p.631.

18. Freeman, F.S. "Factors of Speed and Power in Tests of Intelligence". J.Exper.Psychol, 1931, Vol.14, p.83.

19. Gates, A.I. "Relation of Quality and Speed of Performance". J.Educ.Psychol. 1924, Vol.15, p.129.

20. Gilbert, J.A. "Researches on the Mental and Physical Development of School Children". Stud.Yale.Psych.Lab. 1894, Vol.2, p.40.

21. Hansen, C.F. "Serial Action as a Basic Measure of Motor Capacity". Psychol.Monog. No.140. 1922.

22. Hart, B. and Spearman, C. "Mental Tests of Dementia". J.Abn.Psychol. 1914, Vol.9, p.217.

23. Highsmith, J.A. "Relation of the Rate of Response to Intelligence". Psychol.Monog. 1925. Vol.34, No.3

24. Hunsicker, I.M. "A Study of the Relationship between Rate and Ability". Teachers' College Contrib.Educ., 1925-185.

25. Johnson, C.A. "Studies on the Knee Jerk". Am.J.Physiol. 1927, Vol.82.

26. Kennedy, M. "Speed as a Personality Trait". J.of Social Psychol. 1930, Vol.l.

27. Kirkpatrick, E.A. "Individual Tests of School Children". Psychol.Rev. 1900, Vol.7, p.274.

28. Kohs, S.C. "Measurement of Intelligence". New York, 1923.

29. Lemmon, V.W. "The Relation of Reaction Time to Measures of Intelligence...." Arch.Psychol. 1928, No.94.

30. Iucas, Reterred to in (25).

31. May, M.A. "Psychological Examination in the U.S.Army". Nat.Acad.Sci.Mem. 1921, Vol.15, p.415.

32. McCal1, W.A. "Correlation of Some Psychological and Educational Measurements". Teachers' College Contrib.Educ. 1916, 79. 
33. Peak H. and Boring, E.G. "The Factor of Speed in Inteliligence". J.Exper.Psychol. 1926, Vol.9, p.7l.

34. Porteous, S.D. "Porteous Tests - The Vineland Revision". Vineland, 1919.

35. Root, W.T. "Correlations between Binet Tests and Group Tests". J.Ed.Psychol. 1922, Vol.13, p.286.

36. Rounds, G.H. "Is the latent Time in the Achilles Tendon Reflex a Criterion of Speed in Mental Reactions?" Arch.Psychol. 1928 , No.95.

37. Ruch, G.M. "Speed Factor in Mental Measurements". J.Ed.Research, - 1924, Vol.9

38. Ruch and Koerth, W. "Power" versus "Speed" in Army Alpha. J.Educ.Psychol. 1923, Vol.14, p.193.

39. Rusk, R.R. "Mental Association in Children". Brit.J.Psychol. 1910 - Vol.3.

40. Schlosberg, H. "A Study of the Conditioned Patellar Reflex". J.Exper.Psychol. 1928, Vol.11. p.468.

41. Spearman, C. "Abilities of Man". MacMillan and Co., 1926.

42. Terman, L.M. "The Measurement of Intelligence". Houghton Mifflin, 1926.

43. Thorndike, E.I. "The Measurement of Intelligence". Teachers' College, Columbia University, 1926.

44. Travis, I.E. and Hunter T.A. "Relation between 'Intelligence' and 'Reflex Conduction Rate:". J.Exper.Psychol. 1928. Vol.11., p.342.

45. Travis, I.E. and Young, C.W. "Relations of Reflex Times to Physical Measurements and Intelligence". J.General Psychol. 1930. Vol.3, p.374.

46. Walters, F.C. "Study of Certain Aspects of the Time Factor in Intelifigence". Teachers' College Contrib.Educ. No.248.

47. Webb, "Character and Intelligence". Brit.J.Psychol.Monog. 1915. No.3.

48. Whipple, G.M. "Reaction Time as a Test of Mental Ability". Am.J.Psychol. 1904, Vol.15. p.489.

49. Wild, E.H. "The Influences of Conation on Cognition". Brit.J.Psychol.192. Vol.18. 
50. Wissler, C. "The Correlation of Mental and Physical Tests". Psychol.Monog. 1901. No.16.

51. Woodworth and Wells, "Association Tests".

Psychol.Monog. 1911, No.57.

52. Wyatt, S. "The Quantitative Investigation of Higher Mental Processes". Brit.J.Psychol. 1913, Vol.6, p.l69. 